\title{
Ichthyofauna of the inner shelf of Paraná, Brazil: checklist, geographic distribution, economic importance and conservation status
}

\author{
Daphne Spier * * (D, Humberto Luiz Nadolny Gerum5 Hugo Bornatowski', Riguel Contente², \\ Natalia A S Mattos ${ }^{3}$, Ciro C Vilar ${ }^{4}$ \& Henry Louis Spach ${ }^{1}$ \\ ${ }^{1}$ Universidade Federal do Paraná, Centro de Estudos do Mar, Programa de Pós-Graduação em Sistemas Costeiros e \\ Oceânicos, Pontal do Paraná, PR, Brasil \\ ${ }^{2}$ Instituto Federal do Pará, Campus Marabá Industrial, Marabá, PA, Brasil \\ ${ }^{3}$ Universidade de São Paulo, Escola de Artes, Ciências e Humanidades, São Paulo, SP, Brasil \\ ${ }^{4}$ Universidade Federal do Espírito Santo, Departamento de Oceanografia e Ecologia, Vitória, ES, Brasil \\ ${ }^{5}$ Associação de Pescadores e Aquicultores de Pontal do Sul, Pontal do Paraná, PR, Brasil \\ *Corresponding author: Daphne Spier,e-mail:daphnespier@gmail.com
}

SPIER, D., GERUM, H. L. N., BORNATOWSKI, H., CONTENTE, R., MATTOS, N. A. S., VILAR, C. C., SPACH, H. L. Ichthyofauna of the inner shelf of Paraná, Brazil: checklist, geographic distribution, economic importance and conservation status. Biota Neotropica. 18(2) e20170385. http://dx.doi.org/10.1590/1676-0611-BN-2017-0385

\begin{abstract}
Comprehensive species checklists are essential to effectively implementing preservation and recovery measures, and should assess conservation status, vulnerability degree and anthropogenic threats. This checklist was compiled from fish species recorded in surveys conducted over the last 30 years in the shallow inner continental shelf in the State of Paraná, Brazil. Information on biogeography, conservation status, economic importance and degree of species' vulnerability are provided. A total of 272 fish species were recorded, spanning 25 orders and 88 families. The most speciose family was Sciaenidae (25 species), followed by Carangidae (23), Engraulidae (10), Carcharhinidae (9), Epinephelidae (9) and Paralichthyidae (9). Most species occurring in Paraná's shallow inner continental shelf are restricted to the West Atlantic. In terms of economic importance, 93\% (253) of the species recorded were of fishery, aquaculture or aquaria interest. A notable fraction (39\%) of the recorded species was classified as having moderate to very high vulnerability to extinction. In particular, 28 species $(10 \%)$ were listed as globally endangered, and 34 species $(12 \%)$ were listed as endangered in the Brazilian territory.
\end{abstract}

Keywords: fish assemblage, species list, Southwest Atlantic, vulnerability

\section{Ictiofauna da plataforma interna do Paraná, Brasil: checklist, distribuição geográfica, importância econômica e estado de conservação}

\begin{abstract}
Resumo: Listas abrangentes de espécies são essenciais para a implementação efetiva de medidas de preservação e devem avaliar o estado de conservação e o grau de vulnerabilidade das comunidades ecológicas. Esta lista foi compilada a partir de espécies de peixes registradas em pesquisas realizadas nos últimos 30 anos na plataforma continental interna rasa do Estado do Paraná. Foram fornecidas informações sobre biogeografia, estado de conservação, importância econômica e grau de vulnerabilidade das espécies. Um total de 272 espécies de peixes foram registradas, abrangendo 25 ordens e 88 famílias. A família com maior número de espécies foi Sciaenidae ( 25 espécies), seguida de Carangidae (23), Engraulidae (10), Carcharhinidae (9), Epinephelidae (9) e Paralichthyidae (9). A maioria das espécies registrada na plataforma continental interna do Paraná está limitada ao Atlântico Oeste. Em termos de importância econômica, 93\% (253) das espécies incluídas nesta lista são comercialmente viáveis, seja na pesca, aquicultura ou aquariofilia. Uma fração notável (39\%) das espécies registradas foi classificada como de vulnerabilidade moderada a muito alta. Em particular, 28 espécies (10\%) estão listadas como ameaçadas de extinção em escala global, e 34 espécies (12\%) estão listadas como ameaçadas de extinção no território brasileiro.
\end{abstract}

Palavras-chave: assembleia de peixes, lista de espécies, Atlântico Sudoeste, vulnerabilidade.

\section{Introduction}

The State of Paraná, in southern Brazil, has a $98 \mathrm{~km}$ long coastline, and is cut by two large estuarine complexes, namely, the Paranaguá Bay to the north and the Guaratuba Bay to the south. Its continental shelf extends from 175 to $190 \mathrm{~km}$ offshore, and is dominated by sandy bottoms, and a few rocky substrates (Brandini 2014).

Paraná's continental shelf harbors a rich fauna, particularly in its inner region which is nutrient enriched by the continental drainage system. Like the estuaries, the inner shelf functions as habitat for reproduction 
and development of many fish species; therefore, it performs a vital role in their life cycles (Blaber 2000). In addition, the continental shelf contains several fish species of commercial importance.

There have been several studies on the fish fauna in the Paranaguá Estuarine Complex (Hackradt et al. 2009; Félix-Hackradt et al. 2010; Ignácio \& Spach 2010; Contente et al. 2011; Passos et al. 2012; Pichler et al. 2015, 2017; Possatto et al. 2017) and in the Guaratuba Bay (Chaves \& Corrêa 1998; Chaves \& Vendel 2001). On the other hand, few studies have focused on the continental shelf region, especially those assessing the taxonomic composition of the ichthyofauna (Santos 2006; Carniel 2008; Schwarz-Junior 2010). Of concern is the threat to the region's fish biodiversity, most notably due to overfishing, deposition of dredged sediments, habitat loss, and deployment of new habitats, such as artificial reefs, whose impact on biodiversity is not yet fully understood. In this study, we have compiled a checklist of fish species inhabiting the shallow inner continental shelf of Paraná. Considerations about geographic distribution, conservation status, economic importance, and degree of vulnerability to extinction are provided. This checklist compiles useful information in a single document that should be of great help in devising measures of preservation and species recovery.

\section{Material and Methods}

Data on fish species inhabiting the inner continental shelf of the State of Paraná were compiled from the peer-reviewed literature (Corrêa et al. 1986; Chaves et al. 2003; Godefroid et al. 2004; Costa \& Chaves 2006; Gomes \& Chaves 2006; Santos et al. 2006; Félix et al. 2007a; Félix et al. 2007b; Bornatowski et al. 2009; Hackradt \& Hackradt 2009; Hackradt et al. 2011; Daros et al. 2012; Bornatowski et al. 2014a; Bornatowski et al. 2014b; Rossi-Wongtschowski et al. 2014, Santos et al. 2016) as well as less accessible academic literature (Santos 2006 and Carniel 2008 - master thesis; Schwarz-Junior 2010 and Spier 2016 - PhD thesis) published over the past 30 years. The full extent of Paraná's shallow inner continental shelf was sampled down to the $20 \mathrm{~m}$ isobath, including areas near the mouth of the Paranaguá Estuarine Complex and the Guaratuba Bay (Figure 1). Overall, gillnetting, trawling, and underwater visual census were the main sampling methods used in the studies compiled in this work. Further details on sampling methods and sampling areas are provided in Table 1. The taxonomic classification and nomenclature follows Marceniuk (2005), Craig \& Hastings (2007), Smith \& Craig (2007), Figueiredo \& Menezes (2009), Carvalho-Filho et al. (2010), Menezes et al. (2010) and Eschmeyer et al. (2014). Orders and families are listed according to

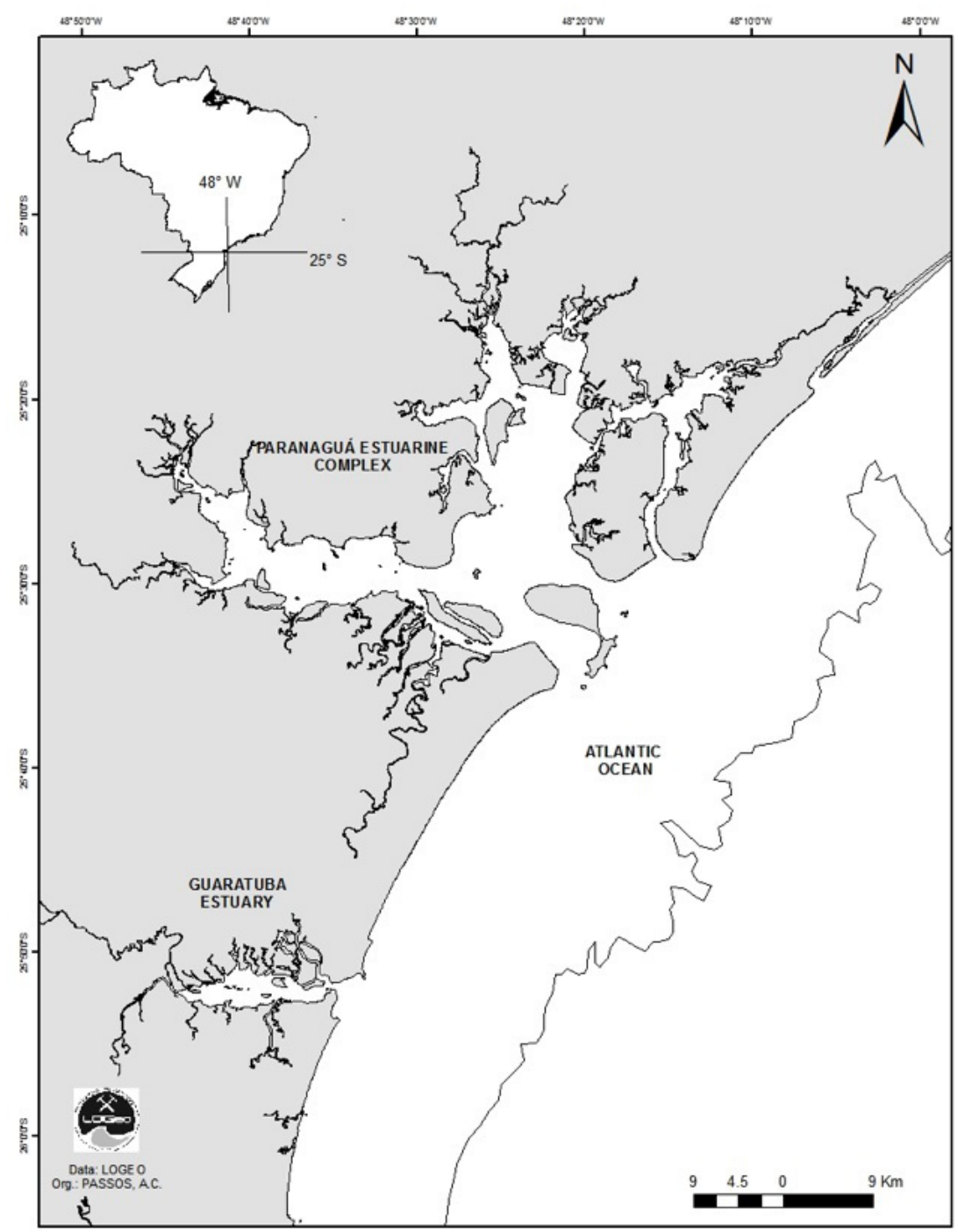

Figure 1. Map of the shallow inner continental shelf of Paraná, Brazil, showing the Paranaguá Estuarine Complex and the Guaratuba estuary. The contour represents the 20 -meter isobath. 
Fishes of shallow inner continental shelf of Paraná, Brazil

Table 1. Details on methods and sampling areas of the different sources consulted. "x"indicates absence of depth data.

\begin{tabular}{|c|c|c|c|c|}
\hline Source & Site & Year & Methods & Isobath \\
\hline Corrêa et al. (1986) & $\begin{array}{l}\text { Coasts of Matinhos, Pontal do Sul, Caiobá } \\
\text { e Mel island }\end{array}$ & until 1986 (since 1942) & Museum collections & $\mathrm{x}$ \\
\hline Chaves et al. (2003) & Matinhos shelf & March 1999 to January 2000 & $\begin{array}{l}\text { Bottom trawl nets } \\
(\text { mesh of } 2.5 \mathrm{~cm})\end{array}$ & 10 and $15 \mathrm{~m}$ \\
\hline Godefroid et al. (2004) & $\begin{array}{l}\text { Shallow infralittoral of Atami Beach } \\
\left(25^{\circ} 30^{\prime} \mathrm{S} ; 48^{\circ} 15^{\prime} \mathrm{W}\right)\end{array}$ & July 1998 to June 1999 & $\begin{array}{l}\text { Bottom trawl nets } \\
(\text { mesh of } 1 \mathrm{~cm})\end{array}$ & 8 and $12 \mathrm{~m}$ \\
\hline Costa \& Chaves (2006) & Paraná Continental Shelf & July 2001 to March 2003 & Trawling and gillnet & 8 to $20 \mathrm{~m}$ \\
\hline Gomes \& Chaves (2006) & $\begin{array}{l}2 \mathrm{~km} \text { from the Guaratuba coast } \\
\left(25^{\circ} 52^{\prime} \mathrm{S} / 48^{\circ} 39^{\prime} \mathrm{W} \text { to } 25^{\circ} 59^{\prime} \mathrm{S} / 48^{\circ} 36^{\prime} \mathrm{W}\right)\end{array}$ & April 2001 to March 2002 & $\begin{array}{l}\text { Bottom trawl nets } \\
(\text { mesh of } 3 \mathrm{~cm})\end{array}$ & $10 \mathrm{~m}$ \\
\hline Santos (2006) & $\begin{array}{l}\text { Paraná Continental Shelf }\left(25^{\circ} 26^{\prime} \mathrm{S} \text { to }\right. \\
\left.25^{\circ} 40^{\prime} \mathrm{S} / 48^{\circ} 08^{\prime} \mathrm{W} \text { to } 48^{\circ} 26^{\prime} \mathrm{W}\right)\end{array}$ & August 2000 to July 2001 & $\begin{array}{l}\text { Bottom trawl nets } \\
(\text { mesh of } 3 \mathrm{~cm})\end{array}$ & 6 to $17 \mathrm{~m}$ \\
\hline Felix et al. (2007) & $\begin{array}{l}\text { Next to the entrance of Paranaguá Bay / } \\
\text { Pontal do Sul beach }\end{array}$ & June 2004 to May 2005 & $\begin{array}{l}\text { Beach seine net, } 15 \mathrm{~m} \text { long } \\
\text { and } 2.6 \mathrm{~m} \text { height - mesh } \\
\text { size of } 5 \mathrm{~mm} .\end{array}$ & $2 \mathrm{~m}$ \\
\hline Carniel (2008) & Paraná Continental Shelf & 2005 and 2006 & Trawling and gillnet & 8 to $20 \mathrm{~m}$ \\
\hline Bornatowski et al. (2009) & PR & until 2009 & $\begin{array}{l}\text { Museum/Literature/ field } \\
\text { surveys }\end{array}$ & $\mathrm{x}$ \\
\hline Hackradt \& Hackradt (2009) & $\begin{array}{l}\text { Currais }\left(25^{\circ} 44^{\prime} \mathrm{S}, 48^{\circ} 22^{\prime} \mathrm{W}\right) \text {, Itacolomis } \\
\left(25^{\circ} 50^{\prime} \mathrm{S}, 48^{\circ} 24^{\prime} \mathrm{W}\right) \text { and Artificial Reefs } \\
\text { between these two islands }\end{array}$ & November 2006 to July 2007 & $\begin{array}{l}\text { Underwater visual census } \\
\text { (SCUBA) }\end{array}$ & 6 to $20 \mathrm{~m}$ \\
\hline Schwarz-Junior (2009) & Paraná Continental Shelf & August 2004 to July 2005 & $\begin{array}{l}\text { Bottom trawl nets } \\
(\text { mesh of } 2.5 \mathrm{~cm})\end{array}$ & $6,9,12$ and $15 \mathrm{~m}$ \\
\hline Hackradt et al. (2011) & $\begin{array}{l}\text { Currais }\left(25^{\circ} 44^{\prime} \mathrm{S}, 48^{\circ} 22^{\prime} \mathrm{W}\right) \text {, Itacolomis } \\
\left(25^{\circ} 50^{\prime} \mathrm{S}, 48^{\circ} 24^{\prime} \mathrm{W}\right) \text { and Artificial Reefs } \\
\text { between these two islands }\end{array}$ & January 2006 to March 2006 & $\begin{array}{l}\text { Underwater visual census } \\
\text { (SCUBA) }\end{array}$ & 6 to $20 \mathrm{~m}$ \\
\hline Daros et al. (2012) & $\begin{array}{l}\text { Currais Archipelago }\left(25^{\circ} 44^{\prime} \mathrm{S}, 48^{\circ} 22^{\prime} \mathrm{W}\right) \\
\text { and Itacolomis Island }\left(25^{\circ} 50^{\prime} \mathrm{S}, 48^{\circ} 24^{\prime} \mathrm{W}\right)\end{array}$ & October 2008 to August 2009 & $\begin{array}{l}\text { Underwater visual census } \\
\text { (SCUBA) }\end{array}$ & 3 to $9 \mathrm{~m}$ \\
\hline Bornatowski et al. (2014a) & $20 \mathrm{~km}$ from the coast & April 2010 to March 2012 & $\begin{array}{l}\text { Gillnet of } 7,9,11,16,18 \\
\text { and } 45 \mathrm{~cm} \text { mesh-size }\end{array}$ & $20 \mathrm{~m}$ \\
\hline Bornatowski et al. (2014b) & Itacolomis Island ( $15 \mathrm{~km}$ from the coast) & September 2011 & Gillnet of $9 \mathrm{~cm}$ mesh-size & 10 and $12 \mathrm{~m}$ \\
\hline Rossi-Wongtschowski et al. (2014) & Paraná Continental Shelf & 1995 to 2010 & $\begin{array}{l}\text { Mid-water trawl nets } \\
(\text { mesh of } 4 \mathrm{~cm})\end{array}$ & 18 to $145 \mathrm{~m}$ \\
\hline Santos et al. (2016) & $\begin{array}{l}\text { Paraná Continental Shelf }\left(25^{\circ} 20^{\prime} \mathrm{S} \text { to }\right. \\
\left.25^{\circ} 50^{\prime} \mathrm{S} / 48^{\circ} 08^{\prime} \mathrm{W} \text { to } 48^{\circ} 26^{\prime} \mathrm{W}\right)\end{array}$ & $\begin{array}{l}\text { August } 2000 \text { to July } 2001 \text { and } \\
\text { August } 2004 \text { and July } 2005\end{array}$ & $\begin{array}{l}\text { Bottom trawl nets } \\
(\text { mesh of } 3 \mathrm{~cm})\end{array}$ & $6,9,12$ and $15 \mathrm{~m}$ \\
\hline Spier (2016) & Islands (Currais, Figueira, Galheta) & 2012 to 2016 & $\begin{array}{l}\text { Underwater visual census } \\
\text { (free dive) }\end{array}$ & 3 to $16 \mathrm{~m}$ \\
\hline
\end{tabular}

phylogenetic order (Eschmeyer et al. 2014) and the species inside each family are organized in alphabetical order.

To analyze the zoogeographic affinities of the fauna, the species were classified in geographic distribution categories based on Floeter et al. (2008), Luiz Jr et al. (2008), Eschmeyer et al. (2014) and Froese \& Pauly (2017). The categories were: $\mathrm{CT}=$ Circumtropical, $\mathrm{TA}=$ Trans-Atlantic (Western and Eastern Atlantic Ocean), WA = Western Atlantic (Northern and Southern Atlantic Ocean), SWA = Southwest Atlantic (ranging from Northern Brazil to Argentina), SSWA = Southern Southwest Atlantic (Southeastern and Southern Brazil, Uruguay and Argentina), $\mathrm{Ca}=$ Caribbean (ranging from Florida to Venezuela), $\mathrm{Br}=$ Brazilian Province [ranging from the Orinoco River Delta in Venezuela to the State of Santa Catarina in Brazil (sensu Briggs \& Bowen 2012)], and EP = Eastern Pacific.

Regarding species' economic importance in Brazil, we defined four categories, namely, 1) food: referring to human consumption, 2) animal feed, 3) aquarium, and 4) none: referring to species without any identified commercial purpose. Categories 1, 2, and 4 were implemented based on the work of Menezes et al. (2003); Figueiredo \& Menezes (2009); Froese $\&$ Pauly (2017), as well as on the authors' previous knowledge. Category 3 was implemented based on the technical and scientific bulletin of CEPENE (2005), which lists marine fish species allowed for capture in Brazil.
Furthermore, we also indicate which species have economic importance specifically for the State of Paraná, based on the authors' knowledge.

Vulnerability to extinction was categorized as low, low to moderate, moderate, moderate to high, high, high to very high, and very high, following FishBase (Froese \& Pauly 2017). These categories were determined based on the life history and ecological characteristics of each species (Cheung et al. 2005). Species were also classified according to the IUCN categories (IUCN 2017) and the national status of conservation proposed by the Brazilian Ministry of Environment (MMA 2014). Conservation status and vulnerability to extinction provide a rough assessment of species' endangerment.

\section{Results}

A total of 272 fish species (234 Actinopterygii and 38 Elasmobranchii) distributed over 25 orders and 88 families were recorded in the shallow inner continental shelf of Paraná (Table 2). The order richest in species was Perciformes (146), followed by Pleuronectiformes (18), Rajiformes (18), Clupeiformes (16) and Carcharhiniformes (15). Sciaenidae was the richest family with 25 species, followed by Carangidae (23), Engraulidae (10), Paralichthyidae (9), Epinephelidae (9) and Carcharhinidae (9). 
Spier, D. et al.

Table 2. Taxonomic classification of the ichthyofauna recorded in the shallow inner shelf of Paraná, Brazil. Geographic Distribution: $\mathrm{CT}=\mathrm{Circuntropical}$, TA $=$ Trans-Atlantic, $\mathrm{WA}=$ Western Atlantic, SWA $=$ Southern West Atlantic, SSWA $=$ Southern Southwest Atlantic, $\mathrm{Ca}=$ Caribbean, $\mathrm{Br}=\mathrm{Brazilian}$ Province and EP $=$ Eastern Pacific. Global conservation status according to IUCN (2010) and national conservation status according to MMA (2014): NE $=$ not evaluated, $L C=$ least concern, $N T=$ near threatened, $\mathrm{DD}=$ data deficient, $\mathrm{VU}=$ vulnerable, $\mathrm{EN}=$ endangered, $\mathrm{CR}=$ critically endangered. Economic importance in Brazil. Asterisk indicate which species have economic importance specifically for the State of Paraná.

\begin{tabular}{|c|c|c|c|c|c|c|}
\hline Orders/Families/Species & $\begin{array}{l}\text { Geographic } \\
\text { Distribution }\end{array}$ & $\begin{array}{l}\text { Economic } \\
\text { Importance }\end{array}$ & $\begin{array}{l}\text { Vulnerability } \\
\text { FishBase }\end{array}$ & $\begin{array}{c}\text { Conservation } \\
\text { status } \\
\text { MMA - } 445 \\
\end{array}$ & $\begin{array}{c}\text { Conservation } \\
\text { status } \\
\text { IUCN } \\
\end{array}$ & Source \\
\hline \multicolumn{7}{|l|}{ Orectolobiformes } \\
\hline \multicolumn{7}{|l|}{ Rhincodontidae } \\
\hline Rhincodon typus Smith, 1828 & $\mathrm{Ta}+\mathrm{EP}$ & No & very high & VU & EN & Bornatowski et al. (2009); Spier (2016) \\
\hline \multicolumn{7}{|l|}{ Carcharhiniformes } \\
\hline \multicolumn{7}{|l|}{ Triakidae } \\
\hline Mustelus canis (Mitchill, 1815) & WA & food* & very high & EN & NT & Bornatowski et al. (2009) \\
\hline $\begin{array}{l}\text { Mustelus schmitti Springer, } \\
1939\end{array}$ & SSWA & food* & high & $\mathrm{CR}$ & EN & $\begin{array}{l}\text { Corrêa et al. (1986); Bornatowski et al. } \\
(2009)\end{array}$ \\
\hline \multicolumn{7}{|l|}{ Carcharhinidae } \\
\hline $\begin{array}{l}\text { Carcharhinus brevipinna } \\
\text { (Müller \& Henle, 1839) }\end{array}$ & $\mathrm{CT}$ & food* & high & DD & NT & Bornatowski et al. (2009) \\
\hline $\begin{array}{l}\text { Carcharhinus falciformis } \\
\text { (Müller \& Henle, 1839) }\end{array}$ & $\mathrm{CT}$ & food* & high & NT & NT & $\begin{array}{l}\text { Costa \& Chaves (2006); Bornatowski et al. } \\
(2009)\end{array}$ \\
\hline $\begin{array}{l}\text { Carcharhinus limbatus (Müller } \\
\text { \& Henle, 1839) }\end{array}$ & $\mathrm{CT}$ & food* & high & NT & NT & $\begin{array}{l}\text { Bornatowski et al. (2009); } \\
\text { Bornatowski et al. (2014a) }\end{array}$ \\
\hline $\begin{array}{l}\text { Carcharhinus plumbeus (Nardo, } \\
\text { 1827) }\end{array}$ & $\mathrm{CT}$ & food* & very high & $\mathrm{CR}$ & VU & Bornatowski et al. (2009) \\
\hline $\begin{array}{l}\text { Carcharhinus porosus } \\
\text { (Ranzani, 1839) }\end{array}$ & $\mathrm{WA}+\mathrm{EP}$ & food* & very high & $\mathrm{CR}$ & DD & $\begin{array}{l}\text { Corrêa et al. (1986); Bornatowski et al. } \\
(2009)\end{array}$ \\
\hline $\begin{array}{l}\text { Carcharhinus obscurus } \\
\text { (Lesueur, 1818) }\end{array}$ & $\mathrm{CT}$ & food* & very high & EN & VU & $\begin{array}{l}\text { Bornatowski et al. (2009), } \\
\text { Bornatowski et al. (2014a) }\end{array}$ \\
\hline $\begin{array}{l}\text { Galeocerdo cuvier } \\
\text { (Péron \& Lesueur, 1822) }\end{array}$ & $\mathrm{CT}$ & food* & high & NT & NT & $\begin{array}{l}\text { Costa \& Chaves (2006); Bornatowski et al. } \\
\text { (2009); Bornatowski et al. (2014a) }\end{array}$ \\
\hline $\begin{array}{l}\text { Rhizoprionodon lalandii } \\
\text { (Müller \& Henle, 1839) }\end{array}$ & $\mathrm{Ca}+\mathrm{SSWA}+\mathrm{Br}$ & food* & moderate & NT & DD & $\begin{array}{l}\text { Costa \& Chaves (2006); Bornatowski et al. } \\
\text { (2009); Bornatowski et al. (2014a) }\end{array}$ \\
\hline $\begin{array}{l}\text { Rhizoprionodon porosus (Poey, } \\
\text { 1861) }\end{array}$ & $\mathrm{Ca}+\mathrm{SSWA}+\mathrm{Br}$ & food* & $\begin{array}{l}\text { moderate to } \\
\text { high }\end{array}$ & DD & $\mathrm{LC}$ & $\begin{array}{l}\text { Costa \& Chaves (2006); Bornatowski et al. } \\
(2009)\end{array}$ \\
\hline \multicolumn{7}{|l|}{ Scyliorhinidae } \\
\hline $\begin{array}{l}\text { Schroederichthys bivius (Müller } \\
\& \text { Henle, 1838) }\end{array}$ & $\mathrm{SSWA}+\mathrm{Br}+\mathrm{EP}$ & animal feed & $\begin{array}{l}\text { moderate to } \\
\text { high }\end{array}$ & - & DD & Bornatowski et al. (2014b) \\
\hline \multicolumn{7}{|l|}{ Sphyrnidae } \\
\hline $\begin{array}{l}\text { Sphyrna lewini (Griffith \& } \\
\text { Smith, 1834) }\end{array}$ & $\mathrm{CT}$ & food* & very high & $\mathrm{CR}$ & EN & $\begin{array}{l}\text { Costa \& Chaves (2006); Santos } \\
\text { (2006); Bornatowski et al. (2009); } \\
\text { Bornatowski et al. (2014a); Santos et al. } \\
\text { (2016) }\end{array}$ \\
\hline $\begin{array}{l}\text { Sphyrna tiburo (Linnaeus, } \\
1758 \text { ) }\end{array}$ & $\mathrm{WA}+\mathrm{EP}$ & food* & $\begin{array}{l}\text { moderate to } \\
\text { high }\end{array}$ & $\mathrm{CR}$ & $\mathrm{LC}$ & Bornatowski et al. (2009) \\
\hline $\begin{array}{l}\text { Sphyrna zygaena (Linnaeus, } \\
1758 \text { ) }\end{array}$ & $\mathrm{CT}$ & food* & very high & CR & VU & $\begin{array}{l}\text { Costa \& Chaves (2006); Bornatowski et al. } \\
\text { (2009); Bornatowski et al. (2014a) }\end{array}$ \\
\hline \multicolumn{7}{|l|}{ Lamniformes } \\
\hline \multicolumn{7}{|l|}{ Odontaspididae } \\
\hline $\begin{array}{l}\text { Carcharias taurus Rafinesque, } \\
1810\end{array}$ & $\mathrm{CT}$ & food* & high & CR & VU & Bornatowski et al. (2009) \\
\hline \multicolumn{7}{|l|}{ Squaliformes } \\
\hline \multicolumn{7}{|l|}{ Squalidae } \\
\hline $\begin{array}{l}\text { Squalus acanthias Linnaeus, } \\
1758\end{array}$ & $\mathrm{CT}$ & food* & $\begin{array}{l}\text { high to very } \\
\text { high }\end{array}$ & $\mathrm{CR}$ & VU & Bornatowski et al. (2009) \\
\hline \multicolumn{7}{|l|}{ Squatiniformes } \\
\hline \multicolumn{7}{|l|}{ Squatinidae } \\
\hline $\begin{array}{l}\text { Squatina guggenheim Marini, } \\
1936\end{array}$ & SWA & food* & high & CR & EN & $\begin{array}{l}\text { Costa \& Chaves (2006); Bornatowski et al. } \\
(2009)\end{array}$ \\
\hline $\begin{array}{l}\text { Squatina occulta Vooren \& da } \\
\text { Silva, } 1992\end{array}$ & SWA & food* & $\begin{array}{l}\text { high to very } \\
\text { high }\end{array}$ & $\mathrm{CR}$ & $\mathrm{EN}$ & Bornatowski et al. (2009) \\
\hline
\end{tabular}


Table 2. Continued...

\begin{tabular}{|c|c|c|c|c|c|c|}
\hline Orders/Families/Species & $\begin{array}{l}\text { Geographic } \\
\text { Distribution }\end{array}$ & $\begin{array}{l}\text { Economic } \\
\text { Importance }\end{array}$ & $\begin{array}{l}\text { Vulnerability } \\
\text { FishBase }\end{array}$ & $\begin{array}{c}\text { Conservation } \\
\text { status } \\
\text { MMA - } 445 \\
\end{array}$ & $\begin{array}{c}\text { Conservation } \\
\text { status } \\
\text { IUCN } \\
\end{array}$ & Source \\
\hline \multicolumn{7}{|l|}{ Rajiformes } \\
\hline \multicolumn{7}{|l|}{ Rhinobatidae } \\
\hline $\begin{array}{l}\text { Pseudobatos horkelii Müller \& } \\
\text { Henle, } 1841\end{array}$ & SWA & food* & $\begin{array}{l}\text { high to very } \\
\text { high }\end{array}$ & CR & $\mathrm{CR}$ & $\begin{array}{l}\text { Chaves et al. (2003); Bornatowski et al. } \\
\text { (2009) }\end{array}$ \\
\hline $\begin{array}{l}\text { Pseudobatos percellens } \\
\text { (Walbaum, 1792) }\end{array}$ & TA & food* & high & DD & NT & $\begin{array}{l}\text { Chaves et al. (2003); Costa \& Chaves } \\
\text { (2006); Santos (2006); Carniel (2008); } \\
\text { Bornatowski et al. (2009); Hackradt \& } \\
\text { Hackradt (2009); Schwarz-Junior (2009); } \\
\text { Santos et al. (2016); Spier (2016) }\end{array}$ \\
\hline $\begin{array}{l}\text { Zapteryx brevirostris (Müller \& } \\
\text { Henle, 1841) }\end{array}$ & SWA & food* & moderate & VU & VU & $\begin{array}{l}\text { Chaves et al. (2003); Costa \& Chaves } \\
\text { (2006); Santos (2006); Carniel (2008); } \\
\text { Bornatowski et al. (2009); Schwarz-Junior } \\
\text { (2009); Santos et al. (2016) }\end{array}$ \\
\hline \multicolumn{7}{|l|}{ Narcinidae } \\
\hline $\begin{array}{l}\text { Narcine brasiliensis (Olfers, } \\
1831 \text { ) }\end{array}$ & WA & No & low to moderate & DD & DD & $\begin{array}{l}\text { Chaves et al. (2003); Godefroid et al. } \\
\text { (2004); Costa \& Chaves (2006); Gomes } \\
\text { \& Chaves (2006); Santos (2006); Carniel } \\
\text { (2008); Bornatowski et al. (2009); } \\
\text { Schwarz-Junior (2009); Santos et al. } \\
(2016)\end{array}$ \\
\hline \multicolumn{7}{|l|}{ Arhynchobatidae } \\
\hline $\begin{array}{l}\text { Atlantoraja castelnaui } \\
\text { (Miranda Ribeiro, 1907) }\end{array}$ & SWA & food & very high & $\mathrm{EN}$ & $\mathrm{EN}$ & Bornatowski et al. (2009) \\
\hline $\begin{array}{l}\text { Atlantoraja cyclophora } \\
\text { (Regan, 1903) }\end{array}$ & WA & food & high & NT & VU & Bornatowski et al. (2009) \\
\hline $\begin{array}{l}\text { Atlantoraja platana (Günther, } \\
1880 \text { ) }\end{array}$ & SWA & food & high & DD & VU & Bornatowski et al. (2009) \\
\hline $\begin{array}{l}\text { Rioraja agassizii } \\
\text { (Müller \& Henle, 1841) }\end{array}$ & SSWA & food* & $\begin{array}{l}\text { high to very } \\
\text { high }\end{array}$ & $\mathrm{EN}$ & VU & $\begin{array}{l}\text { Costa \& Chaves (2006); Bornatowski et al. } \\
(2009)\end{array}$ \\
\hline \multicolumn{7}{|l|}{ Dasyatidae } \\
\hline $\begin{array}{l}\text { Hypanus americanus Hildebrand } \\
\text { \& Schroeder, } 1928\end{array}$ & WA & food* & very high & DD & DD & $\begin{array}{l}\text { Costa \& Chaves (2006); Bornatowski et al. } \\
(2009)\end{array}$ \\
\hline $\begin{array}{l}\text { Hypanus guttatus } \\
\text { (Bloch \& Schneider, 1801) }\end{array}$ & $\mathrm{Ca}+\mathrm{Br}$ & food* & very high & - & DD & $\begin{array}{l}\text { Costa \& Chaves (2006); Bornatowski et al. } \\
\text { (2009); Schwarz-Junior (2009); } \\
\text { Santos et al. (2016); Spier (2016) }\end{array}$ \\
\hline $\begin{array}{l}\text { Dasyatis hypostigma Santos \& } \\
\text { Carvalho, } 2004\end{array}$ & SWA & food* & $\begin{array}{l}\text { high to very } \\
\text { high }\end{array}$ & DD & DD & $\begin{array}{l}\text { Costa \& Chaves (2006); Bornatowski et al. } \\
\text { (2009); Spier (2016) }\end{array}$ \\
\hline \multicolumn{7}{|l|}{ Gymnuridae } \\
\hline $\begin{array}{l}\text { Gymnura altavela (Linnaeus, } \\
1758 \text { ) }\end{array}$ & TA & food* & $\begin{array}{l}\text { moderate to } \\
\text { high }\end{array}$ & CR & $\mathrm{VU}$ & $\begin{array}{l}\text { Costa \& Chaves (2006); Santos (2006); } \\
\text { Bornatowski et al. (2009); Santos et al. } \\
(2016) ; \text { Spier (2016) }\end{array}$ \\
\hline \multicolumn{7}{|l|}{ Myliobatidae } \\
\hline $\begin{array}{l}\text { Aetobatus narinari } \\
\text { (Euphrasen, 1790) }\end{array}$ & $\mathrm{CT}$ & food* & $\begin{array}{l}\text { high to very } \\
\text { high }\end{array}$ & DD & NT & $\begin{array}{l}\text { Bornatowski et al. (2009); Hackradt \& } \\
\text { Hackradt (2009); Daros et al. (2012); Spier } \\
(2016)\end{array}$ \\
\hline $\begin{array}{l}\text { Mobula birostris (Walbaum, } \\
\text { 1792) }\end{array}$ & $\mathrm{CT}$ & No & very high & VU & $\mathrm{VU}$ & $\begin{array}{l}\text { Bornatowski et al. (2009); Hackradt \& } \\
\text { Hackradt (2009); Spier (2016) }\end{array}$ \\
\hline $\begin{array}{l}\text { Mobula hypostoma (Bancroft, } \\
\text { 1831) }\end{array}$ & WA & No & high & VU & DD & Bornatowski et al. (2009) \\
\hline $\begin{array}{l}\text { Myliobatis goodei Garman, } \\
1885\end{array}$ & $\mathrm{CT}$ & food* & $\begin{array}{l}\text { moderate to } \\
\text { high }\end{array}$ & CR & DD & $\begin{array}{l}\text { Costa \& Chaves (2006); Bornatowski et al. } \\
(2009)\end{array}$ \\
\hline \multicolumn{7}{|l|}{ Rhinopteridae } \\
\hline $\begin{array}{l}\text { Rhinoptera bonasus (Mitchill, } \\
\text { 1815) }\end{array}$ & TA & food* & high & DD & NT & $\begin{array}{l}\text { Corrêa et al. (1986); Bornatowski et al. } \\
\text { (2009); Schwarz-Junior (2009); } \\
\text { Santos et al. (2016) }\end{array}$ \\
\hline $\begin{array}{l}\text { Rhinoptera brasiliensis Müller, } \\
1836\end{array}$ & SWA & food* & $\begin{array}{l}\text { moderate to } \\
\text { high }\end{array}$ & CR & EN & Bornatowski et al. (2009); Spier (2016) \\
\hline \multicolumn{7}{|l|}{ Elopiformes } \\
\hline \multicolumn{7}{|l|}{ Elopidae } \\
\hline Elops saurus Linnaeus, 1766 & WA & animal feed & moderate & - & $\mathrm{LC}$ & Carniel (2008); Spier (2016) \\
\hline
\end{tabular}


Spier, D. et al.

Table 2. Continued...

\begin{tabular}{|c|c|c|c|c|c|c|}
\hline Orders/Families/Species & $\begin{array}{l}\text { Geographic } \\
\text { Distribution }\end{array}$ & $\begin{array}{l}\text { Economic } \\
\text { Importance }\end{array}$ & $\begin{array}{l}\text { Vulnerability } \\
\text { FishBase }\end{array}$ & $\begin{array}{c}\text { Conservation } \\
\text { status } \\
\text { MMA - } 445 \\
\end{array}$ & $\begin{array}{c}\text { Conservation } \\
\text { status } \\
\text { IUCN } \\
\end{array}$ & Source \\
\hline \multicolumn{7}{|l|}{ Anguilliformes } \\
\hline \multicolumn{7}{|l|}{ Muraenidae } \\
\hline $\begin{array}{l}\text { Gymnothorax funebris Ranzani, } \\
1839\end{array}$ & WA & aquarium / food & $\begin{array}{l}\text { high to very } \\
\text { high }\end{array}$ & DD & $\mathrm{LC}$ & $\begin{array}{l}\text { Hackradt \& Hackradt (2009); } \\
\text { Hackradt et al. (2011); Daros et al. (2012); } \\
\text { Spier (2016) }\end{array}$ \\
\hline $\begin{array}{l}\text { Gymnothorax miliaris (Kaup, } \\
1856 \text { ) }\end{array}$ & TA & aquarium & moderate & - & $\mathrm{LC}$ & Spier (2016) \\
\hline $\begin{array}{l}\text { Gymnothorax moringa (Cuvier, } \\
1829 \text { ) }\end{array}$ & WA & aquarium / food & very high & DD & $\mathrm{LC}$ & $\begin{array}{l}\text { Hackradt \& Hackradt (2009); } \\
\text { Hackradt et al. (2011); Daros et al. (2012); } \\
\text { Spier (2016) }\end{array}$ \\
\hline $\begin{array}{l}\text { Gymnothorax ocellatus } \\
\text { Agassiz, } 1831\end{array}$ & $\mathrm{SWA}+\mathrm{Ca}$ & aquarium & high & DD & $\mathrm{LC}$ & $\begin{array}{l}\text { Santos (2006); Carniel (2008); Schwarz- } \\
\text { Junior (2009); Santos et al. (2016) }\end{array}$ \\
\hline $\begin{array}{l}\text { Gymnothorax vicinus } \\
\text { (Castelnau, 1855) }\end{array}$ & TA & aquarium / food & high & DD & $\mathrm{LC}$ & $\begin{array}{l}\text { Hackradt \& Hackradt (2009); } \\
\text { Hackradt et al. (2011); Daros et al. (2012); } \\
\text { Spier (2016) }\end{array}$ \\
\hline \multicolumn{7}{|l|}{ Ophichthidae } \\
\hline $\begin{array}{l}\text { Myrichthys breviceps } \\
\text { (Richardson, 1848) }\end{array}$ & WA & aquarium & $\begin{array}{l}\text { moderate to } \\
\text { high }\end{array}$ & - & $\mathrm{LC}$ & Daros et al. (2012); Spier (2016) \\
\hline $\begin{array}{l}\text { Ophichthus gomesii (Castelnau, } \\
1855)\end{array}$ & WA & No & high & - & $\mathrm{LC}$ & $\begin{array}{l}\text { Gomes \& Chaves (2006); Santos (2006); } \\
\text { Carniel (2008); Schwarz-Junior (2009); } \\
\text { Santos et al. (2016) }\end{array}$ \\
\hline \multicolumn{7}{|l|}{ Muraenesocidae } \\
\hline $\begin{array}{l}\text { Cynoponticus savanna } \\
\text { (Bancroft, 1831) }\end{array}$ & $\mathrm{Ca}+\mathrm{Br}$ & No & $\begin{array}{l}\text { high to very } \\
\text { high }\end{array}$ & - & $\mathrm{LC}$ & Godefroid et al. (2004) \\
\hline \multicolumn{7}{|l|}{ Clupeiformes } \\
\hline \multicolumn{7}{|l|}{ Clupeidae } \\
\hline $\begin{array}{l}\text { Harengula clupeola (Cuvier, } \\
\text { 1829) }\end{array}$ & WA & animal feed* & low & - & $\mathrm{LC}$ & $\begin{array}{l}\text { Chaves et al. (2003); Godefroid et al. } \\
\text { (2004); Santos (2006); Felix et al. } \\
\text { (2007); Carniel (2008); Hackradt \& } \\
\text { Hackradt (2009); Schwarz-Junior } \\
\text { (2009); Hackradt et al. (2011); Rossi- } \\
\text { Wongtschowski et al. (2014); Santos et al. } \\
\text { (2016); Spier (2016) }\end{array}$ \\
\hline $\begin{array}{l}\text { Opisthonema oglinum } \\
\text { (Lesueur, 1818) }\end{array}$ & WA & food* & low to moderate & - & $\mathrm{LC}$ & $\begin{array}{l}\text { Corrêa et al. (1986); Felix et al. } \\
\text { (2007); Schwarz Junior (2009); Rossi- } \\
\text { Wongtschowski et al. (2014); Santos et al. } \\
(2016)\end{array}$ \\
\hline $\begin{array}{l}\text { Platanichthys platana (Regan, } \\
\text { 1917) }\end{array}$ & SSWA & animal feed* & low & - & $\mathrm{NE}$ & $\begin{array}{l}\text { Felix et al. (2007); Schwarz Junior (2009); } \\
\text { Santos et al. (2016) }\end{array}$ \\
\hline $\begin{array}{l}\text { Sardinella brasiliensis } \\
\text { (Steindachner, 1879) }\end{array}$ & SSWA & food* & low & DD & $\mathrm{NE}$ & $\begin{array}{l}\text { Godefroid et al. (2004); Santos (2006); } \\
\text { Felix et al. (2007); Carniel (2008); } \\
\text { Hackradt \& Hackradt (2009); Schwarz- } \\
\text { Junior (2009); Hackradt et al. (2011); } \\
\text { Rossi-Wongtschowski et al. (2014); } \\
\text { Santos et al. (2016); Spier (2016) }\end{array}$ \\
\hline \multicolumn{7}{|l|}{ Engraulidae } \\
\hline Anchoa filifera (Fowler, 1915) & $\mathrm{Ca}+\mathrm{Br}$ & food & low & - & $\mathrm{LC}$ & $\begin{array}{l}\text { Corrêa et al. (1986); Gomes \& Chaves } \\
(2006)\end{array}$ \\
\hline $\begin{array}{l}\text { Anchoa lyolepis (Evermann \& } \\
\text { Marsh, 1900) }\end{array}$ & WA & food* & low & - & $\mathrm{LC}$ & $\begin{array}{l}\text { Godefroid et al. (2004); Gomes \& Chaves } \\
\text { (2006); Santos (2006); Felix et al. (2007); } \\
\text { Schwarz-Junior (2009); Santos et al. } \\
(2016)\end{array}$ \\
\hline $\begin{array}{l}\text { Anchoa parva (Meek \& } \\
\text { Hildebrand 1923) }\end{array}$ & WA & food & low & - & $\mathrm{LC}$ & $\begin{array}{l}\text { Félix et al. (2007); Carniel (2008); } \\
\text { Schwarz-Junior (2009); Santos et al. } \\
(2016)\end{array}$ \\
\hline $\begin{array}{l}\text { Anchoa spinifer (Valenciennes, } \\
1848 \text { ) }\end{array}$ & $\mathrm{Ca}+\mathrm{Br}+\mathrm{EP}$ & food & low & - & $\mathrm{LC}$ & $\begin{array}{l}\text { Santos (2006); Carniel(2008); Schwarz } \\
\text { Junior (2009); Santos et al. (2016) }\end{array}$ \\
\hline $\begin{array}{l}\text { Anchoa tricolor (Spix \& } \\
\text { Agassiz, 1829) }\end{array}$ & SWA & food* & low & - & $\mathrm{NE}$ & $\begin{array}{l}\text { Corrêa et al. (1986); Godefroid et al. } \\
\text { (2004); Santos (2006); Felix et al. (2007); } \\
\text { Carniel (2008); Schwarz-Junior (2009); } \\
\text { Rossi-Wongtschowski et al. (2014); } \\
\text { Santos et al. (2016) }\end{array}$ \\
\hline
\end{tabular}


Table 2. Continued...

\begin{tabular}{|c|c|c|c|c|c|c|}
\hline Orders/Families/Species & $\begin{array}{l}\text { Geographic } \\
\text { Distribution }\end{array}$ & $\begin{array}{l}\text { Economic } \\
\text { Importance }\end{array}$ & $\begin{array}{l}\text { Vulnerability } \\
\text { FishBase }\end{array}$ & $\begin{array}{c}\text { Conservation } \\
\text { status } \\
\text { MMA-445 }\end{array}$ & $\begin{array}{l}\text { Conservation } \\
\text { status } \\
\text { IUCN } \\
\end{array}$ & Source \\
\hline $\begin{array}{l}\text { Anchovia clupeoides } \\
\text { (Swainson, 1839) }\end{array}$ & $\mathrm{Ca}+\mathrm{Br}$ & food & low & - & $\mathrm{LC}$ & $\begin{array}{l}\text { Carniel (2008); Schwarz Junior (2009); } \\
\text { Santos et al. (2016) }\end{array}$ \\
\hline $\begin{array}{l}\text { Anchoviella lepidentostole } \\
\text { (Fowler, 1911) }\end{array}$ & $\mathrm{Br}$ & food & low & - & $\mathrm{LC}$ & $\begin{array}{l}\text { Gomes \& Chaves (2006); Santos (2006); } \\
\text { Santos et al. (2016); Santos et al. (2016); } \\
\text { Spier (2016) }\end{array}$ \\
\hline $\begin{array}{l}\text { Cetengraulis edentulus (Cuvier, } \\
\text { 1829) }\end{array}$ & $\mathrm{Ca}+\mathrm{Br}$ & animal feed* & moderate & - & $\mathrm{LC}$ & $\begin{array}{l}\text { Corrêa et al. (1986); Godefroid et al. } \\
\text { (2004); Gomes \& Chaves (2006); Santos } \\
\text { (2006); Felix et al. (2007); Carniel (2008); } \\
\text { Schwarz-Junior (2009); Santos et al. } \\
\text { (2016) }\end{array}$ \\
\hline $\begin{array}{l}\text { Engraulis anchoita Hubbs \& } \\
\text { Marini, } 1935\end{array}$ & SSWA & food & moderate & - & $\mathrm{NE}$ & $\begin{array}{l}\text { Santos (2006); Rossi-Wongtschowski et al. } \\
\text { (2014); Santos et al. (2016) }\end{array}$ \\
\hline $\begin{array}{l}\text { Lycengraulis grossidens (Spix } \\
\text { \& Agassiz, 1829) }\end{array}$ & SWA & food* & low to moderate & - & $\mathrm{LC}$ & $\begin{array}{l}\text { Chaves et al. (2003); Godefroid et al. } \\
\text { (2004); Gomes \& Chaves (2006); Santos } \\
\text { (2006); Felix et al. (2007); Carniel } \\
\text { (2008); Schwarz-Junior (2009); Rossi- } \\
\text { Wongtschowski et al. (2014); Santos et al. } \\
\text { (2016) }\end{array}$ \\
\hline \multicolumn{7}{|l|}{ Pristigasteridae } \\
\hline $\begin{array}{l}\text { Chirocentrodon bleekerianus } \\
\text { (Poey, 1867) }\end{array}$ & $\mathrm{Ca}+\mathrm{Br}$ & animal feed & low & - & $\mathrm{LC}$ & $\begin{array}{l}\text { Chaves et al. (2003); Godefroid et al. } \\
\text { (2004); Gomes \& Chaves (2006); Santos } \\
\text { (2006); Carniel (2008); Schwarz-Junior } \\
\text { (2009); Rossi-Wongtschowski et al. } \\
\text { (2014); Santos et al. (2016) }\end{array}$ \\
\hline $\begin{array}{l}\text { Pellona harroweri (Fowler, } \\
\text { 1917) }\end{array}$ & $\mathrm{Ca}+\mathrm{Br}$ & animal feed & low & - & $\mathrm{LC}$ & $\begin{array}{l}\text { Chaves et al. (2003); Godefroid et al. } \\
\text { (2004); Gomes \& Chaves (2006); Santos } \\
\text { (2006); Carniel (2008); Schwarz-Junior } \\
\text { (2009); Rossi-Wongtschowski et al. } \\
\text { (2014); Santos et al. (2016) }\end{array}$ \\
\hline \multicolumn{7}{|l|}{ Siluriformes } \\
\hline \multicolumn{7}{|l|}{ Ariidae } \\
\hline $\begin{array}{l}\text { Aspistor luniscutis } \\
\text { (Valenciennes, 1840) }\end{array}$ & $\mathrm{Br}$ & food* & low & - & $\mathrm{NE}$ & $\begin{array}{l}\text { Gomes \& Chaves (2006); Carniel (2008); } \\
\text { Schwarz-Junior (2009); Santos et al. } \\
\text { (2016) }\end{array}$ \\
\hline Bagre bagre (Linnaeus, 1766) & $\mathrm{Ca}+\mathrm{Br}$ & food* & $\begin{array}{l}\text { moderate to } \\
\text { high }\end{array}$ & NT & $\mathrm{LC}$ & $\begin{array}{l}\text { Corrêa et al. (1986); Santos (2006); } \\
\text { Carniel (2008); Schwarz-Junior (2009); } \\
\text { Santos et al. (2016) }\end{array}$ \\
\hline Bagre marinus (Mitchill, 1815) & WA & food* & high & - & $\mathrm{LC}$ & Carniel (2008) \\
\hline $\begin{array}{l}\text { Cathorops spixii (Spix \& } \\
\text { Agassiz, 1829) }\end{array}$ & $\mathrm{Ca}+\mathrm{Br}$ & food* & moderate & - & $\mathrm{NE}$ & $\begin{array}{l}\text { Chaves et al. (2003); Gomes \& Chaves } \\
\text { (2006); Santos (2006); Carniel (2008); } \\
\text { Schwarz-Junior (2009); Santos et al. } \\
(2016)\end{array}$ \\
\hline $\begin{array}{l}\text { Genidens barbus (Lacepède, } \\
1803 \text { ) }\end{array}$ & SSWA & food* & high & EN & $\mathrm{NE}$ & $\begin{array}{l}\text { Chaves et al. (2003); Gomes \& Chaves } \\
\text { (2006); Santos (2006); Carniel (2008); } \\
\text { Schwarz-Junior (2009); Spier (2016); } \\
\text { Santos et al. (2016) }\end{array}$ \\
\hline $\begin{array}{l}\text { Genidens genidens (Cuvier, } \\
\text { 1829) }\end{array}$ & SSWA & food* & moderate & - & $\mathrm{LC}$ & $\begin{array}{l}\text { Godefroid et al. (2004); Gomes \& Chaves } \\
\text { (2006); Santos (2006); Schwarz-Junior } \\
\text { (2009); Santos et al. (2016) }\end{array}$ \\
\hline $\begin{array}{l}\text { Notarius grandicassis } \\
\text { (Valenciennes, } 1840 \text { ) }\end{array}$ & $\mathrm{Br}$ & food* & $\begin{array}{l}\text { moderate to } \\
\text { high }\end{array}$ & - & $\mathrm{LC}$ & $\begin{array}{l}\text { Schwarz Junior (2009); Santos et al. } \\
\text { (2016) }\end{array}$ \\
\hline \multicolumn{7}{|l|}{ Stomiiformes } \\
\hline \multicolumn{7}{|l|}{ Sternoptychidae } \\
\hline $\begin{array}{l}\text { Maurolicus stehmanni Parin \& } \\
\text { Kobyliansky, } 1993\end{array}$ & SWA & animal feed & low & - & $\mathrm{NE}$ & Rossi-Wongtschowski et al. (2014) \\
\hline \multicolumn{7}{|l|}{ Aulopiformes } \\
\hline \multicolumn{7}{|l|}{ Synodontidae } \\
\hline $\begin{array}{l}\text { Saurida brasiliensis Norman, } \\
1935\end{array}$ & $\mathrm{Ta}$ & animal feed & low & - & $\mathrm{LC}$ & Rossi-Wongtschowski et al. (2014) \\
\hline
\end{tabular}


Spier, D. et al.

Table 2. Continued..

\begin{tabular}{|c|c|c|c|c|c|c|}
\hline Orders/Families/Species & $\begin{array}{l}\text { Geographic } \\
\text { Distribution }\end{array}$ & $\begin{array}{l}\text { Economic } \\
\text { Importance }\end{array}$ & $\begin{array}{l}\text { Vulnerability } \\
\text { FishBase }\end{array}$ & $\begin{array}{c}\text { Conservation } \\
\text { status } \\
\text { MMA - } 445 \\
\end{array}$ & $\begin{array}{c}\text { Conservation } \\
\text { status } \\
\text { IUCN } \\
\end{array}$ & Source \\
\hline $\begin{array}{l}\text { Synodus foetens (Linnaeus, } \\
1766 \text { ) }\end{array}$ & WA & aquarium & low to moderate & - & $\mathrm{LC}$ & $\begin{array}{l}\text { Chaves et al. (2003); Santos (2006); } \\
\text { Felix et al. (2007); Hackradt \& Hackradt } \\
\text { (2009); Hackradt et al. (2011); Rossi- } \\
\text { Wongtschowski et al. (2014); Santos et al. } \\
\text { (2016) }\end{array}$ \\
\hline $\begin{array}{l}\text { Synodus synodus (Linnaeus, } \\
1758 \text { ) }\end{array}$ & $\mathrm{TA}$ & aquarium & low & - & $\mathrm{LC}$ & $\begin{array}{l}\text { Hackradt \& Hackradt (2009); } \\
\text { Hackradt et al. (2011); Daros et al. (2012) }\end{array}$ \\
\hline \multicolumn{7}{|l|}{ Gadiformes } \\
\hline \multicolumn{7}{|l|}{ Bregmacerotidae } \\
\hline $\begin{array}{l}\text { Bregmaceros atlanticus Goode } \\
\text { \& Bean, } 1886\end{array}$ & $\mathrm{CT}$ & No & low & - & $\mathrm{LC}$ & Rossi-Wongtschowski et al. (2014) \\
\hline $\begin{array}{l}\text { Bregmaceros cantori Milliken } \\
\text { \& Houde, } 1984\end{array}$ & $\mathrm{Ca}+\mathrm{Br}$ & No & low & - & $\mathrm{LC}$ & Rossi-Wongtschowski et al. (2014) \\
\hline \multicolumn{7}{|l|}{ Phycidae } \\
\hline $\begin{array}{l}\text { Urophycis brasiliensis (Kaup, } \\
\text { 1858) }\end{array}$ & SSWA & food* & moderate & NT & NE & $\begin{array}{l}\text { Chaves et al. (2003); Godefroid et al. } \\
\text { (2004); Gomes \& Chaves (2006); Santos } \\
\text { (2006); Carniel (2008); Schwarz-Junior } \\
\text { (2009); Santos et al. (2016) }\end{array}$ \\
\hline $\begin{array}{l}\text { Urophycis mystacea } \text { Miranda } \\
\text { Ribeiro, } 1903\end{array}$ & SSWA & animal feed & low & NT & $\mathrm{NE}$ & Rossi-Wongtschowski et al. (2014) \\
\hline \multicolumn{7}{|l|}{ Merlucciidae } \\
\hline Merluccius hubbsi Marini, 1933 & SSWA & food* & high & NT & $\mathrm{NE}$ & Rossi-Wongtschowski et al. (2014) \\
\hline \multicolumn{7}{|l|}{ Batrachoidiformes } \\
\hline \multicolumn{7}{|l|}{ Batrachoididae } \\
\hline $\begin{array}{l}\text { Porichthys porosissimus } \\
\text { (Cuvier, 1829) }\end{array}$ & SSWA & aquarium & moderate & - & $\mathrm{NE}$ & $\begin{array}{l}\text { Chaves et al. (2003); Godefroid et al. } \\
\text { (2004); Gomes \& Chaves (2006); Santos } \\
\text { (2006); Carniel (2008); Schwarz-Junior } \\
\text { (2009); Rossi-Wongtschowski et al. } \\
\text { (2014); Santos et al. (2016) }\end{array}$ \\
\hline \multicolumn{7}{|l|}{ Lophiiformes } \\
\hline \multicolumn{7}{|l|}{ Ogcocephalidae } \\
\hline $\begin{array}{l}\text { Ogcocephalus vespertilio } \\
\text { (Linnaeus, 1758) }\end{array}$ & $\mathrm{SWA}+\mathrm{Ca}$ & aquarium & moderate & - & $\mathrm{NE}$ & $\begin{array}{l}\text { Corrêa et al. (1986); Santos (2006); } \\
\text { Hackradt \& Hackradt (2009); Schwarz- } \\
\text { Junior (2009); Hackradt et al. (2011); } \\
\text { Santos et al. (2016) }\end{array}$ \\
\hline \multicolumn{7}{|l|}{ Gobiesociformes } \\
\hline \multicolumn{7}{|l|}{ Gobiesocidae } \\
\hline Gobiesox strumosus Cope, 1870 & WA+EP & aquarium & low to moderate & - & $\mathrm{LC}$ & Corrêa et al. (1986) \\
\hline \multicolumn{7}{|l|}{ Atheriniformes } \\
\hline \multicolumn{7}{|l|}{ Atherinopsidae } \\
\hline $\begin{array}{l}\text { Atherinella brasiliensis (Quoy } \\
\text { \& Gaimard, 1825) }\end{array}$ & WA & animal feed* & low & - & $\mathrm{LC}$ & Corrêa et al. (1986); Spier (2016) \\
\hline $\begin{array}{l}\text { Odontesthes bonariensis } \\
\text { (Valenciennes, 1835) }\end{array}$ & SSWA & food & low to moderate & DD & $\mathrm{NE}$ & Félix et al. (2007) \\
\hline \multicolumn{7}{|l|}{ Beloniformes } \\
\hline \multicolumn{7}{|l|}{ Belonidae } \\
\hline $\begin{array}{l}\text { Strongylura timиси (Walbaum, } \\
\text { 1792) }\end{array}$ & WA & animal feed & moderate & - & $\mathrm{LC}$ & Félix et al. (2007); Spier (2016) \\
\hline \multicolumn{7}{|l|}{ Hemiramphidae } \\
\hline $\begin{array}{l}\text { Hemiramphus brasiliensis } \\
\text { (Linnaeus, 1758) }\end{array}$ & TA & food* & low to moderate & - & $\mathrm{LC}$ & $\begin{array}{l}\text { Godefroid et al. (2004); Hackradt \& } \\
\text { Hackradt (2009); Spier (2016) }\end{array}$ \\
\hline $\begin{array}{l}\text { Hyporhamphus unifasciatus } \\
\text { (Ranzani, 1841) }\end{array}$ & WA+EP & food* & low & NT & $\mathrm{LC}$ & $\begin{array}{l}\text { Godefroid et al. (2004); Félix et al. (2007); } \\
\text { Hackradt \& Hackradt (2009) }\end{array}$ \\
\hline \multicolumn{7}{|l|}{ Syngnathiformes } \\
\hline \multicolumn{7}{|l|}{ Syngnathidae } \\
\hline $\begin{array}{l}\text { Hippocampus erectus Perry, } \\
1810\end{array}$ & WA & aquarium & low to moderate & VU & VU & Santos (2006); Santos et al. (2016) \\
\hline
\end{tabular}


Table 2. Continued...

\begin{tabular}{|c|c|c|c|c|c|c|}
\hline Orders/Families/Species & $\begin{array}{l}\text { Geographic } \\
\text { Distribution }\end{array}$ & $\begin{array}{l}\text { Economic } \\
\text { Importance }\end{array}$ & $\begin{array}{l}\text { Vulnerability } \\
\text { FishBase }\end{array}$ & $\begin{array}{c}\text { Conservation } \\
\text { status } \\
\text { MMA - } 445 \\
\end{array}$ & $\begin{array}{c}\text { Conservation } \\
\text { status } \\
\text { IUCN } \\
\end{array}$ & Source \\
\hline $\begin{array}{l}\text { Micrognathus crinitus (Jenyns, } \\
\text { 1842) }\end{array}$ & WA & No & low & - & $\mathrm{LC}$ & $\begin{array}{l}\text { Hackradt \& Hackradt (2009); } \\
\text { Hackradt et al. (2011); Daros et al. (2012) }\end{array}$ \\
\hline Syngnathus folletti Herald, 1942 & SWA & No & low to moderate & - & $\mathrm{LC}$ & $\begin{array}{l}\text { Félix et al. (2007); Schwarz-Junior (2009); } \\
\text { Santos et al. (2016) }\end{array}$ \\
\hline \multicolumn{7}{|l|}{ Scorpaeniformes } \\
\hline \multicolumn{7}{|l|}{ Scorpaenidae } \\
\hline $\begin{array}{l}\text { Scorpaena brasiliensis Cuvier, } \\
1829\end{array}$ & WA & aquarium & $\begin{array}{l}\text { moderate to } \\
\text { high }\end{array}$ & - & $\mathrm{LC}$ & Hackradt et al. (2011); Daros et al. (2012) \\
\hline $\begin{array}{l}\text { Scorpaena isthmensis Meek \& } \\
\text { Hildebrand, } 1928\end{array}$ & WA & aquarium & low to moderate & - & $\mathrm{LC}$ & Santos (2006); Santos et al. (2016) \\
\hline $\begin{array}{l}\text { Scorpaena plumieri Bloch, } \\
1789\end{array}$ & TA & aquarium & high & - & $\mathrm{LC}$ & $\begin{array}{l}\text { Hackradt \& Hackradt (2009); } \\
\text { Hackradt et al. (2011); Spier (2016) }\end{array}$ \\
\hline Dactylopteridae & & & & - & & \\
\hline $\begin{array}{l}\text { Dactylopterus volitans } \\
\text { (Linnaeus, 1758) }\end{array}$ & TA & aquarium & moderate & - & LC & $\begin{array}{l}\text { Santos (2006); Félix et al. (2007); } \\
\text { Carniel (2008); Schwarz-Junior } \\
\text { (2009); Daros et al. (2012); Rossi- } \\
\text { Wongtschowski et al. (2014); Santos et al. } \\
\text { (2016) }\end{array}$ \\
\hline Triglidae & & & & - & & \\
\hline $\begin{array}{l}\text { Prionotus nudigula Ginsburg, } \\
1950\end{array}$ & SSWA & aquarium & $\begin{array}{l}\text { moderate to } \\
\text { high }\end{array}$ & - & $\mathrm{NE}$ & $\begin{array}{l}\text { Gomes \& Chaves (2006); Santos (2006); } \\
\text { Félix et al. (2007); Schwarz-Junior (2009); } \\
\text { Santos et al. (2016) }\end{array}$ \\
\hline $\begin{array}{l}\text { Prionotus punctatus (Bloch, } \\
1793\end{array}$ & $\mathrm{SWA}+\mathrm{Ca}$ & food* & $\begin{array}{l}\text { moderate to } \\
\text { high }\end{array}$ & - & $\mathrm{LC}$ & $\begin{array}{l}\text { Chaves et al. (2003); Godefroid et al. } \\
\text { (2004); Gomes \& Chaves (2006); Santos } \\
\text { (2006); Felix et al. (2007); Carniel (2008); } \\
\text { Hackradt \& Hackradt (2009); Schwarz- } \\
\text { Junior (2009); Rossi-Wongtschowski et al. } \\
\text { (2014); Santos et al. (2016) }\end{array}$ \\
\hline \multicolumn{7}{|l|}{ Perciformes } \\
\hline \multicolumn{7}{|l|}{ Centropomidae } \\
\hline $\begin{array}{l}\text { Centropomus parallelus Poey, } \\
1860\end{array}$ & WA & food* & high & - & $\mathrm{LC}$ & $\begin{array}{l}\text { Corrêa et al. (1986); Chaves et al. (2003); } \\
\text { Felix et al. (2007); Schwarz-Junior (2009); } \\
\text { Santos et al. (2016) }\end{array}$ \\
\hline $\begin{array}{l}\text { Centropomus undecimalis } \\
\text { (Bloch, 1792) }\end{array}$ & $\mathrm{WA}+\mathrm{Ca}$ & food* & $\begin{array}{c}\text { moderate to } \\
\text { high }\end{array}$ & - & $\mathrm{LC}$ & Hackradt \& Hackradt (2009); Spier (2016) \\
\hline \multicolumn{7}{|l|}{ Acropomatidae } \\
\hline $\begin{array}{l}\text { Synagrops spinosus Schultz, } \\
1940\end{array}$ & WA+EP & No & low & - & $\mathrm{LC}$ & Rossi-Wongtschowski et al. (2014) \\
\hline \multicolumn{7}{|l|}{ Serranidae } \\
\hline $\begin{array}{l}\text { Diplectrum formosum } \\
\text { (Linnaeus, 1766) }\end{array}$ & WA & aquarium & low & - & $\mathrm{LC}$ & $\begin{array}{l}\text { Chaves et al. (2003); Santos (2006); } \\
\text { Santos et al. (2016) }\end{array}$ \\
\hline $\begin{array}{l}\text { Diplectrum radiale (Quoy \& } \\
\text { Gaimard, 1824) }\end{array}$ & WA & aquarium & low to moderate & - & $\mathrm{LC}$ & $\begin{array}{l}\text { Chaves et al. (2003); Santos (2006); } \\
\text { Carniel (2008); Schwarz-Junior (2009); } \\
\text { Hackradt et al. (2011); Daros et al. (2012); } \\
\text { Santos et al. (2016); Spier (2016) }\end{array}$ \\
\hline Dules auriga Cuvier 1829 & SSWA & aquarium & low & - & $\mathrm{NE}$ & Santos (2006); Santos et al. (2016) \\
\hline $\begin{array}{l}\text { Serranus flaviventris (Cuvier, } \\
\text { 1829) }\end{array}$ & WA & aquarium & low & - & $\mathrm{LC}$ & $\begin{array}{l}\text { Hackradt \& Hackradt (2009); } \\
\text { Hackradt et al. (2011); Daros et al. (2012); } \\
\text { Spier (2016) }\end{array}$ \\
\hline \multicolumn{7}{|l|}{ Epinephelidae } \\
\hline $\begin{array}{l}\text { Epinephelus itajara } \\
\text { (Lichtenstein, 1822) }\end{array}$ & $\mathrm{Ta}$ & food* & $\begin{array}{l}\text { high to very } \\
\text { high }\end{array}$ & $\mathrm{CR}$ & $\mathrm{CR}$ & $\begin{array}{l}\text { Hackradt \& Hackradt (2009); Hackradt et al. } \\
\text { (2011); Spier (2016) }\end{array}$ \\
\hline $\begin{array}{l}\text { Epinephelus marginatus (Lowe, } \\
\text { 1834) }\end{array}$ & $\mathrm{TA}$ & food* & $\begin{array}{l}\text { high to very } \\
\text { high }\end{array}$ & VU & EN & $\begin{array}{l}\text { Hackradt \& Hackradt (2009); } \\
\text { Hackradt et al. (2011); Daros et al. (2012); } \\
\text { Spier (2016) }\end{array}$ \\
\hline $\begin{array}{l}\text { Epinephelus morio } \\
\text { (Valenciennes, 1828) }\end{array}$ & WA & food* & high & VU & NT & Carniel (2008); Daros et al. (2012) \\
\hline
\end{tabular}


Spier, D. et al.

Table 2. Continued...

\begin{tabular}{|c|c|c|c|c|c|c|}
\hline Orders/Families/Species & $\begin{array}{l}\text { Geographic } \\
\text { Distribution }\end{array}$ & $\begin{array}{l}\text { Economic } \\
\text { Importance }\end{array}$ & $\begin{array}{l}\text { Vulnerability } \\
\text { FishBase }\end{array}$ & $\begin{array}{c}\text { Conservation } \\
\text { status } \\
\text { MMA - } 445 \\
\end{array}$ & $\begin{array}{c}\text { Conservation } \\
\text { status } \\
\text { IUCN } \\
\end{array}$ & Source \\
\hline $\begin{array}{l}\text { Hyporthodus nigritus } \\
\text { (Holbrook, 1855) }\end{array}$ & WA & food* & $\begin{array}{l}\text { high to very } \\
\text { high }\end{array}$ & $\mathrm{EN}$ & $\mathrm{CR}$ & $\begin{array}{l}\text { Santos (2006), Hackradt \& Hackradt } \\
\text { (2009); Santos et al. (2016); Spier (2016) }\end{array}$ \\
\hline $\begin{array}{l}\text { Hyporthodus niveatus } \\
\text { (Valenciennes, 1828) }\end{array}$ & WA & food* & high & VU & VU & $\begin{array}{l}\text { Hackradt \& Hackradt (2009); } \\
\text { Hackradt et al. (2011); Daros et al. (2012); } \\
\text { Spier (2016) }\end{array}$ \\
\hline $\begin{array}{l}\text { Mycteroperca acutirostris } \\
\text { (Valenciennes, 1828) }\end{array}$ & $\mathrm{Ca}+\mathrm{Br}$ & food* & high & DD & $\mathrm{LC}$ & $\begin{array}{l}\text { Santos (2006); Hackradt \& Hackradt } \\
\text { (2009); Hackradt et al. (2011); Daros et al. } \\
\text { (2012); Santos et al. (2016); Spier (2016) }\end{array}$ \\
\hline $\begin{array}{l}\text { Mycteroperca bonaci (Poey, } \\
1860 \text { ) }\end{array}$ & WA & food* & high & VU & NT & $\begin{array}{l}\text { Hackradt \& Hackradt (2009); } \\
\text { Hackradt et al. (2011); Daros et al. (2012); } \\
\text { Spier (2016) }\end{array}$ \\
\hline $\begin{array}{l}\text { Mycteroperca microlepis } \\
\text { (Goode \& Bean, 1879) }\end{array}$ & WA & food* & $\begin{array}{l}\text { high to very } \\
\text { high }\end{array}$ & DD & $\mathrm{LC}$ & $\begin{array}{l}\text { Hackradt \& Hackradt (2009); Hackradt et al. } \\
\text { (2011); Spier (2016) }\end{array}$ \\
\hline $\begin{array}{l}\text { Rypticus randalli Courtenay, } \\
1967\end{array}$ & $\mathrm{Ca}+\mathrm{Br}$ & No & low & - & LC & $\begin{array}{l}\text { Chaves et al. (2003); Gomes \& Chaves } \\
\text { (2006); Santos (2006); Carniel (2008); } \\
\text { Schwarz-Junior (2009); Santos et al. } \\
(2016)\end{array}$ \\
\hline \multicolumn{7}{|l|}{ Priacanthidae } \\
\hline $\begin{array}{l}\text { Heteropriacanthus cruentatus } \\
\text { (Lacepède, 1801) }\end{array}$ & CT & aquarium & low to moderate & - & $\mathrm{LC}$ & Rossi-Wongtschowski et al. (2014) \\
\hline $\begin{array}{l}\text { Priacanthus arenatus Cuvier, } \\
1829\end{array}$ & TA & food* & low to moderate & - & $\mathrm{LC}$ & $\begin{array}{l}\text { Corrêa et al. (1986); Hackradt \& } \\
\text { Hackradt (2009); Schwarz-Junior } \\
\text { (2009); Daros et al. (2012); Rossi- } \\
\text { Wongtschowski et al. (2014); Santos et al. } \\
\text { (2016); Spier (2016) }\end{array}$ \\
\hline \multicolumn{7}{|l|}{ Malacanthidae } \\
\hline $\begin{array}{l}\text { Malacanthus plumieri (Bloch, } \\
1786 \text { ) }\end{array}$ & WA & No & high & - & $\mathrm{LC}$ & Spier (2016) \\
\hline \multicolumn{7}{|l|}{ Pomatomidae } \\
\hline $\begin{array}{l}\text { Pomatomus saltatrix (Linnaeus, } \\
1766 \text { ) }\end{array}$ & CT & food* & high & NT & $\mathrm{VU}$ & $\begin{array}{l}\text { Godefroid et al. (2004); Santos (2006); } \\
\text { Felix et al. (2007); Carniel (2008); } \\
\text { Hackradt \& Hackradt (2009); Schwarz- } \\
\text { Junior (2009); Hackradt et al. (2011); } \\
\text { Rossi-Wongtschowski et al. (2014); } \\
\text { Santos et al. (2016); Spier (2016) }\end{array}$ \\
\hline \multicolumn{7}{|l|}{ Rachycentridae } \\
\hline $\begin{array}{l}\text { Rachycentron canadum } \\
\text { (Linnaeus, 1766) }\end{array}$ & CT & food* & moderate & - & LC & $\begin{array}{l}\text { Carniel (2008); Hackradt \& Hackradt } \\
\text { (2009); Spier (2016) }\end{array}$ \\
\hline \multicolumn{7}{|l|}{ Echeneidae } \\
\hline $\begin{array}{l}\text { Echeneis naucrates Linnaeus, } \\
1758\end{array}$ & TA & aquarium & $\begin{array}{l}\text { moderate to } \\
\text { high }\end{array}$ & - & $\mathrm{LC}$ & Hackradt \& Hackradt (2009); Spier (2016) \\
\hline $\begin{array}{l}\text { Remora remora (Linnaeus, } \\
1758 \text { ) }\end{array}$ & TA & food & $\begin{array}{l}\text { moderate to } \\
\text { high }\end{array}$ & - & $\mathrm{LC}$ & Hackradt \& Hackradt (2009); Spier (2016) \\
\hline \multicolumn{7}{|l|}{ Carangidae } \\
\hline Alectis ciliaris (Bloch, 1787) & $\mathrm{Ta}+\mathrm{EP}$ & food* & $\begin{array}{l}\text { high to very } \\
\text { high }\end{array}$ & - & $\mathrm{LC}$ & Spier (2016) \\
\hline $\begin{array}{l}\text { Carangoides bartholomaei } \\
\text { (Cuvier, 1833) }\end{array}$ & WA & food* & high & - & $\mathrm{LC}$ & $\begin{array}{l}\text { Godefroid et al. (2004); Carniel (2008); } \\
\text { Schwartz-Junior (2009); Santos et al. } \\
(2016)\end{array}$ \\
\hline Caranx crysos (Mitchill, 1815) & TA & food* & low to moderate & - & $\mathrm{LC}$ & $\begin{array}{l}\text { Santos (2006); Hackradt \& Hackradt } \\
\text { (2009); Hackradt et al. (2011); Daros et al. } \\
\text { (2012); Santos et al. (2016); Spier (2016) }\end{array}$ \\
\hline $\begin{array}{l}\text { Caranx hippos (Linnaeus, } \\
1766 \text { ) }\end{array}$ & TA & food* & high & - & $\mathrm{LC}$ & Carniel (2008); Spier (2016) \\
\hline Caranx latus Agassiz, 1831 & TA & food* & high & - & $\mathrm{LC}$ & $\begin{array}{l}\text { Corrêa et al. (1986); Gomes \& Chaves } \\
\text { (2006); Santos (2006); Carniel } \\
\text { (2008); Hackradt \& Hackradt (2009); } \\
\text { Hackradt et al. (2011); Daros et al. (2012); } \\
\text { Santos et al. (2016); Spier (2016) }\end{array}$ \\
\hline Caranx ruber (Bloch, 1793) & WA & food* & high & - & $\mathrm{LC}$ & Godefroid et al. (2004); Spier (2016) \\
\hline
\end{tabular}


Table 2. Continued...

\begin{tabular}{|c|c|c|c|c|c|c|}
\hline Orders/Families/Species & $\begin{array}{l}\text { Geographic } \\
\text { Distribution }\end{array}$ & $\begin{array}{l}\text { Economic } \\
\text { Importance }\end{array}$ & $\begin{array}{l}\text { Vulnerability } \\
\text { FishBase }\end{array}$ & $\begin{array}{c}\text { Conservation } \\
\text { status } \\
\text { MMA - } 445 \\
\end{array}$ & $\begin{array}{c}\text { Conservation } \\
\text { status } \\
\text { IUCN }\end{array}$ & Source \\
\hline $\begin{array}{l}\text { Chloroscombrus chrysurus } \\
\text { (Linnaeus, 1766) }\end{array}$ & TA & food* & $\begin{array}{l}\text { moderate to } \\
\text { high }\end{array}$ & - & $\mathrm{LC}$ & $\begin{array}{l}\text { Chaves et al. (2003); Godefroid et al. } \\
\text { (2004); Gomes \& Chaves (2006); Santos } \\
\text { (2006); Felix et al. (2007); Carniel } \\
\text { (2008); Hackradt \& Hackradt (2009); } \\
\text { Schwarz-Junior (2009); Hackradt et al. } \\
\text { (2011); Daros et al. (2012); Rossi- } \\
\text { Wongtschowski et al. (2014); Santos et al. } \\
\text { (2016); Spier (2016) }\end{array}$ \\
\hline $\begin{array}{l}\text { Hemicaranx amblyrhynchus } \\
\text { (Cuvier, 1833) }\end{array}$ & WA & food* & low to moderate & - & $\mathrm{LC}$ & $\begin{array}{l}\text { Chaves et al. (2003); Carniel (2008); Spier } \\
\text { (2016) }\end{array}$ \\
\hline $\begin{array}{l}\text { Oligoplites palometa (Cuvier, } \\
\text { 1832) }\end{array}$ & $\mathrm{Ca}+\mathrm{Br}$ & food* & low to moderate & - & $\mathrm{LC}$ & $\begin{array}{l}\text { Santos (2006); Santos et al. (2016); Spier } \\
(2016)\end{array}$ \\
\hline $\begin{array}{l}\text { Oligoplites saliens (Bloch, } \\
1793 \text { ) }\end{array}$ & $\mathrm{SWA}+\mathrm{Ca}$ & aquarium* & moderate & - & $\mathrm{LC}$ & $\begin{array}{l}\text { Corrêa et al. (1986); Santos (2006); } \\
\text { Felix et al. (2007); Carniel (2008); } \\
\text { Hackradt \& Hackradt (2009); Schwarz- } \\
\text { Junior (2009); Hackradt et al. (2011); } \\
\text { Rossi-Wongtschowski et al. (2014); } \\
\text { Santos et al. (2016) }\end{array}$ \\
\hline $\begin{array}{l}\text { Oligoplites saurus (Bloch \& } \\
\text { Schneider, 1801) }\end{array}$ & WA & food* & low to moderate & - & $\mathrm{LC}$ & Godefroid et al. (2004) \\
\hline $\begin{array}{l}\text { Pseudocaranx dentex (Bloch \& } \\
\text { Schneider, 1801) }\end{array}$ & $\mathrm{CT}$ & food* & $\begin{array}{l}\text { high to very } \\
\text { high }\end{array}$ & - & $\mathrm{LC}$ & $\begin{array}{l}\text { Hackradt \& Hackradt (2009); } \\
\text { Hackradt et al. (2011); Daros et al. (2012); } \\
\text { Spier (2016) }\end{array}$ \\
\hline $\begin{array}{l}\text { Selene setapinnis (Mitchill, } \\
1815 \text { ) }\end{array}$ & WA & food* & low to moderate & - & $\mathrm{LC}$ & $\begin{array}{l}\text { Chaves et al. (2003); Godefroid et al. } \\
\text { (2004); Gomes \& Chaves (2006); Santos } \\
\text { (2006); Carniel (2008); Hackradt \& } \\
\text { Hackradt (2009); Schwarz-Junior (2009); } \\
\text { Rossi-Wongtschowski et al. (2014); } \\
\text { Santos et al. (2016); Spier (2016) }\end{array}$ \\
\hline Selene vomer (Linnaeus, 1758) & WA & aquarium* & moderate & - & $\mathrm{LC}$ & $\begin{array}{l}\text { Chaves et al. (2003); Godefroid et al. } \\
\text { (2004); Gomes \& Chaves (2006); Santos } \\
\text { (2006); Felix et al. (2007); Carniel (2008); } \\
\text { Schwarz-Junior (2009); Daros et al. } \\
\text { (2012); Rossi-Wongtschowski et al. } \\
\text { (2014); Santos et al. (2016); Spier (2016) }\end{array}$ \\
\hline Seriola dumerili (Risso, 1810) & CT & food* & $\begin{array}{l}\text { moderate to } \\
\text { high }\end{array}$ & - & $\mathrm{LC}$ & $\begin{array}{l}\text { Santos (2006); Hackradt \& Hackradt } \\
\text { (2009); Santos et al. (2016) }\end{array}$ \\
\hline $\begin{array}{l}\text { Seriola lalandi Valenciennes, } \\
1833\end{array}$ & $\mathrm{TA}+\mathrm{EP}$ & food* & $\begin{array}{l}\text { high to very } \\
\text { high }\end{array}$ & - & $\mathrm{LC}$ & Spier (2016) \\
\hline $\begin{array}{l}\text { Seriola rivoliana Valenciennes, } \\
1833\end{array}$ & WA+EP & food* & $\begin{array}{l}\text { high to very } \\
\text { high }\end{array}$ & - & $\mathrm{LC}$ & $\begin{array}{l}\text { Hackradt \& Hackradt (2009); } \\
\text { Hackradt et al. (2011); Spier (2016) }\end{array}$ \\
\hline $\begin{array}{l}\text { Trachinotus carolinus (Linnaeus, } \\
\text { 1766) }\end{array}$ & WA & food* & $\begin{array}{l}\text { moderate to } \\
\text { high }\end{array}$ & - & $\mathrm{LC}$ & $\begin{array}{l}\text { Chaves et al. (2003); Godefroid et al. } \\
\text { (2004); Gomes \& Chaves (2006); } \\
\text { Felix et al. (2007); Carniel (2008); } \\
\text { Schwarz-Junior (2009); Santos et al. } \\
\text { (2016); Spier (2016) }\end{array}$ \\
\hline $\begin{array}{l}\text { Trachinotus falcatus (Linnaeus, } \\
1758 \text { ) }\end{array}$ & WA & food* & moderate & - & $\mathrm{LC}$ & $\begin{array}{l}\text { Corrêa et al. (1986); Felix et al. (2007); } \\
\text { Hackradt \& Hackradt (2009); Spier (2016) }\end{array}$ \\
\hline $\begin{array}{l}\text { Trachinotus goodei Jordan \& } \\
\text { Evermann, } 1896\end{array}$ & WA & food* & low to moderate & - & $\mathrm{LC}$ & Félix et al. (2007); Spier (2016) \\
\hline $\begin{array}{l}\text { Trachinotus marginatus Cuvier, } \\
1832\end{array}$ & SSWA & food* & $\begin{array}{l}\text { moderate to } \\
\text { high }\end{array}$ & - & $\mathrm{NE}$ & $\begin{array}{l}\text { Godefroid et al. (2004); Félix et al. (2007); } \\
\text { Spier (2016) }\end{array}$ \\
\hline $\begin{array}{l}\text { Trachurus lathami Nichols, } \\
1920\end{array}$ & WA & food & moderate & - & $\mathrm{LC}$ & Rossi-Wongtschowski et al. (2014) \\
\hline Uraspis secunda (Poey, 1860) & $\mathrm{CT}$ & No & low to moderate & - & $\mathrm{LC}$ & Godefroid et al. (2004) \\
\hline \multicolumn{7}{|l|}{ Coryphaenidae } \\
\hline $\begin{array}{l}\text { Coryphaena hippurus Linnaeus, } \\
1758\end{array}$ & $\mathrm{CT}$ & food* & moderate & - & $\mathrm{LC}$ & $\begin{array}{l}\text { Rossi-Wongtschowski et al. (2014); Spier } \\
\text { (2016) }\end{array}$ \\
\hline Lutjanidae & & & & & & \\
\hline
\end{tabular}


Table 2. Continued...

\begin{tabular}{|c|c|c|c|c|c|c|}
\hline Orders/Families/Species & $\begin{array}{l}\text { Geographic } \\
\text { Distribution }\end{array}$ & $\begin{array}{c}\text { Economic } \\
\text { Importance }\end{array}$ & $\begin{array}{l}\text { Vulnerability } \\
\text { FishBase }\end{array}$ & $\begin{array}{c}\text { Conservation } \\
\text { status } \\
\text { MMA - } 445\end{array}$ & $\begin{array}{c}\text { Conservation } \\
\text { status } \\
\text { IUCN } \\
\end{array}$ & Source \\
\hline Lutjanus analis (Cuvier, 1828) & $\mathrm{WA}+\mathrm{Ca}$ & food* & $\begin{array}{l}\text { moderate to } \\
\text { high }\end{array}$ & NT & NT & $\begin{array}{l}\text { Hackradt \& Hackradt (2009); } \\
\text { Hackradt et al. (2011); Daros et al. (2012); } \\
\text { Spier (2016) }\end{array}$ \\
\hline $\begin{array}{l}\text { Lutjanus cyanopterus (Cuvier, } \\
1828 \text { ) }\end{array}$ & WA & food* & high & VU & VU & Hackradt \& Hackradt (2009); Spier (2016) \\
\hline $\begin{array}{l}\text { Lutjanus griseus (Linnaeus, } \\
1758 \text { ) }\end{array}$ & $\mathrm{WA}+\mathrm{Ca}$ & food* & moderate & - & $\mathrm{LC}$ & Spier (2016) \\
\hline $\begin{array}{l}\text { Lutjanus jocu }(\text { Bloch \& } \\
\text { Schneider, 1801) }\end{array}$ & $\mathrm{Ta}$ & food* & $\begin{array}{l}\text { high to very } \\
\text { high }\end{array}$ & NT & DD & Spier (2016) \\
\hline $\begin{array}{l}\text { Lutjanus synagris (Linnaeus, } \\
1758 \text { ) }\end{array}$ & $\mathrm{WA}+\mathrm{Ca}$ & food* & moderate & NT & NT & $\begin{array}{l}\text { Hackradt \& Hackradt (2009); } \\
\text { Hackradt et al. (2011); Spier (2016) }\end{array}$ \\
\hline $\begin{array}{l}\text { Rhomboplites aurorubens } \\
\text { (Cuvier, 1829) }\end{array}$ & $\mathrm{WA}+\mathrm{Ca}$ & food & $\begin{array}{l}\text { moderate to } \\
\text { high }\end{array}$ & NT & $\mathrm{VU}$ & $\begin{array}{l}\text { Hackradt \& Hackradt (2009); } \\
\text { Hackradt et al. (2011); Rossi- } \\
\text { Wongtschowski et al. (2014) }\end{array}$ \\
\hline \multicolumn{7}{|l|}{ Lobotidae } \\
\hline $\begin{array}{l}\text { Lobotes surinamensis (Bloch, } \\
1790)\end{array}$ & CT & food* & low to moderate & - & LC & Carniel (2008); Spier (2016) \\
\hline \multicolumn{7}{|l|}{ Gerreidae } \\
\hline $\begin{array}{l}\text { Diapterus auratus Ranzani, } \\
1842\end{array}$ & WA & food* & low to moderate & - & LC & Corrêa et al. (1986); Spier (2016) \\
\hline $\begin{array}{l}\text { Diapterus rhombeus (Cuvier, } \\
\text { 1829) }\end{array}$ & $\mathrm{Ca}+\mathrm{Br}$ & food* & moderate & - & $\mathrm{LC}$ & $\begin{array}{l}\text { Chaves et al. (2003); Godefroid et al. } \\
\text { (2004); Gomes \& Chaves (2006); Santos } \\
\text { (2006); Felix et al. (2007); Carniel (2008); } \\
\text { Hackradt \& Hackradt (2009); Schwarz- } \\
\text { Junior (2009); Rossi-Wongtschowski et al. } \\
\text { (2014); Santos et al. (2016) }\end{array}$ \\
\hline $\begin{array}{l}\text { Eucinostomus argenteus Baird } \\
\text { \& Girard, } 1855\end{array}$ & $\mathrm{WA}+\mathrm{EP}$ & food* & low & - & $\mathrm{LC}$ & $\begin{array}{l}\text { Chaves et al. (2003); Godefroid et al. } \\
\text { (2004); Gomes \& Chaves (2006); Santos } \\
\text { (2006); Felix et al. (2007); Carniel (2008); } \\
\text { Hackradt \& Hackradt (2009); Schwarz- } \\
\text { Junior (2009); Hackradt et al. (2011); } \\
\text { Rossi-Wongtschowski et al. (2014); } \\
\text { Santos et al. (2016) }\end{array}$ \\
\hline $\begin{array}{l}\text { Eucinostomus gula (Quoy \& } \\
\text { Gaimard, 1824) }\end{array}$ & WA & food* & low to moderate & - & LC & $\begin{array}{l}\text { Chaves et al. (2003); Santos (2006); } \\
\text { Schwarz-Junior (2009); Santos et al. } \\
(2016)\end{array}$ \\
\hline Ulaema lefroyi (Goode, 1874) & $\mathrm{Ca}+\mathrm{Br}$ & food* & low & - & $\mathrm{LC}$ & Félix et al. (2007) \\
\hline $\begin{array}{l}\text { Eucinostomus melanopterus } \\
\text { (Bleeker, 1863) }\end{array}$ & TA & food* & low to moderate & - & $\mathrm{LC}$ & $\begin{array}{l}\text { Gomes \& Chaves (2006); Felix et al. } \\
\text { (2007); Carniel (2008); Schwarz-Junior } \\
\text { (2009); Santos et al. (2016) }\end{array}$ \\
\hline $\begin{array}{l}\text { Eugerres brasilianus (Cuvier, } \\
1830 \text { ) }\end{array}$ & WA & food* & moderate & - & LC & Corrêa et al. (1986), Carniel (2008) \\
\hline \multicolumn{7}{|l|}{ Haemulidae } \\
\hline $\begin{array}{l}\text { Anisotremus surinamensis } \\
\text { (Bloch, 1791) }\end{array}$ & WA & aquarium / food* & high & DD & DD & $\begin{array}{l}\text { Chaves et al. (2003); Godefroid et al. } \\
\text { (2004); Gomes \& Chaves (2006); Hackradt } \\
\text { \& Hackradt (2009); Hackradt et al. (2011); } \\
\text { Daros et al. (2012); Spier (2016) }\end{array}$ \\
\hline $\begin{array}{l}\text { Anisotremus virginicus } \\
\text { (Linnaeus, 1758) }\end{array}$ & WA & aquarium & moderate & - & $\mathrm{LC}$ & $\begin{array}{l}\text { Carniel (2008); Hackradt \& Hackradt } \\
\text { (2009); Hackradt et al. (2011); Daros et al. } \\
\text { (2012); Spier (2016) }\end{array}$ \\
\hline $\begin{array}{l}\text { Conodon nobilis (Linnaeus, } \\
1758 \text { ) }\end{array}$ & WA & aquarium & low to moderate & - & LC & $\begin{array}{l}\text { Chaves et al. (2003); Godefroid et al. } \\
\text { (2004); Gomes \& Chaves (2006); Santos } \\
\text { (2006); Felix et al. (2007); Carniel (2008); } \\
\text { Schwarz-Junior (2009); Santos et al. } \\
(2016)\end{array}$ \\
\hline $\begin{array}{l}\text { Genyatremus luteus (Bloch, } \\
1790)\end{array}$ & $\mathrm{Ca}+\mathrm{Br}$ & food* & low to moderate & - & DD & Corrêa et al. (1986), Carniel (2008) \\
\hline $\begin{array}{l}\text { Haemulon aurolineatum Cuvier, } \\
1830\end{array}$ & WA & food* & moderate & - & LC & $\begin{array}{l}\text { Hackradt \& Hackradt (2009); } \\
\text { Hackradt et al. (2011); Daros et al. (2012); } \\
\text { Spier (2016) }\end{array}$ \\
\hline
\end{tabular}


Table 2. Continued...

\begin{tabular}{|c|c|c|c|c|c|c|}
\hline Orders/Families/Species & $\begin{array}{l}\text { Geographic } \\
\text { Distribution }\end{array}$ & $\begin{array}{c}\text { Economic } \\
\text { Importance }\end{array}$ & $\begin{array}{l}\text { Vulnerability } \\
\text { FishBase }\end{array}$ & $\begin{array}{c}\text { Conservation } \\
\text { status } \\
\text { MMA - } 445\end{array}$ & $\begin{array}{c}\text { Conservation } \\
\text { status } \\
\text { IUCN }\end{array}$ & Source \\
\hline $\begin{array}{l}\text { Haemulopsis corvinaeformis } \\
\text { (Steindachner 1868) }\end{array}$ & WA & aquarium & low to moderate & - & $\mathrm{LC}$ & $\begin{array}{l}\text { Godefroid et al. (2004); Gomes \& Chaves } \\
\text { (2006); Santos (2006); Felix et al. (2007); } \\
\text { Carniel (2008); Schwarz-Junior (2009); } \\
\text { Santos et al. (2016) }\end{array}$ \\
\hline $\begin{array}{l}\text { Haemulon steindachneri } \\
\text { (Jordan \& Gilbert, 1882) }\end{array}$ & $\mathrm{SWA}+\mathrm{Ca}$ & aquarium & low to moderate & - & $\mathrm{LC}$ & $\begin{array}{l}\text { Godefroid et al. (2004); Hackradt \& } \\
\text { Hackradt (2009); Hackradt et al. (2011); } \\
\text { Daros et al. (2012); Spier (2016) }\end{array}$ \\
\hline Orthopristis ruber (Cuvier, 1830) & $\mathrm{SWA}+\mathrm{Ca}$ & aquarium & moderate & - & $\mathrm{LC}$ & $\begin{array}{l}\text { Chaves et al. (2003); Godefroid et al. } \\
\text { (2004); Santos (2006); Carniel (2008); } \\
\text { Hackradt \& Hackradt (2009); Schwarz- } \\
\text { Junior (2009); Hackradt et al. (2011); } \\
\text { Rossi-Wongtschowski et al. (2014); } \\
\text { Santos et al. (2016); Spier (2016) }\end{array}$ \\
\hline \multicolumn{7}{|l|}{ Sparidae } \\
\hline $\begin{array}{l}\text { Archosargus probatocephalus } \\
\text { (Walbaum, 1792) }\end{array}$ & WA & food* & moderate & DD & $\mathrm{LC}$ & $\begin{array}{l}\text { Hackradt \& Hackradt (2009); } \\
\text { Hackradt et al. (2011); Daros et al. (2012); } \\
\text { Spier (2016) }\end{array}$ \\
\hline $\begin{array}{l}\text { Archosargus rhomboidalis } \\
\text { (Linnaeus, 1758) }\end{array}$ & WA & aquarium* & moderate & - & $\mathrm{LC}$ & Carniel (2008); Spier (2016) \\
\hline $\begin{array}{l}\text { Diplodus argenteus argenteus } \\
\text { (Valenciennes, 1830) }\end{array}$ & WA & food* & low to moderate & - & $\mathrm{LC}$ & $\begin{array}{l}\text { Hackradt \& Hackradt (2009); } \\
\text { Hackradt et al. (2011); Daros et al. (2012); } \\
\text { Spier (2016) }\end{array}$ \\
\hline \multicolumn{7}{|l|}{ Sciaenidae } \\
\hline Bairdiella ronchus (Cuvier, 1830) & $\mathrm{Ca}+\mathrm{Br}$ & animal feed & low to moderate & - & $\mathrm{LC}$ & $\begin{array}{l}\text { Chaves et al. (2003); Godefroid et al. } \\
\text { (2004); Gomes \& Chaves (2006); Santos } \\
\text { (2006); Carniel (2008); Schwarz-Junior } \\
\text { (2009); Santos et al. (2016) }\end{array}$ \\
\hline $\begin{array}{l}\text { Ctenosciaena gracilicirrhus } \\
\text { (Metzelaar, 1919) }\end{array}$ & $\mathrm{Ca}+\mathrm{Br}$ & animal feed & low & - & $\mathrm{LC}$ & $\begin{array}{l}\text { Gomes \& Chaves (2006); Santos (2006); } \\
\text { Felix et al. (2007); Carniel (2008); } \\
\text { Schwarz-Junior (2009); Santos et al. } \\
(2016)\end{array}$ \\
\hline $\begin{array}{l}\text { Cynoscion acoupa (Lacepède, } \\
1801 \text { ) }\end{array}$ & $\mathrm{SWA}+\mathrm{Ca}$ & food* & high & NT & $\mathrm{LC}$ & $\begin{array}{l}\text { Gomes \& Chaves (2006); Santos (2006); } \\
\text { Carniel (2008); Schwarz-Junior (2009); } \\
\text { Santos et al. (2016); Spier (2016) }\end{array}$ \\
\hline $\begin{array}{l}\text { Cynoscion jamaicensis (Vaillant } \\
\text { \& Bocourt, 1883) }\end{array}$ & $\mathrm{SWA}+\mathrm{Ca}$ & food* & moderate & - & $\mathrm{LC}$ & $\begin{array}{l}\text { Godefroid et al. (2004); Gomes \& Chaves } \\
\text { (2006); Santos (2006); Carniel (2008); } \\
\text { Schwarz-Junior (2009); Santos et al. } \\
(2016)\end{array}$ \\
\hline $\begin{array}{l}\text { Cynoscion leiarchus (Cuvier, } \\
1830 \text { ) }\end{array}$ & $\mathrm{Ca}+\mathrm{Br}$ & food* & high & - & $\mathrm{LC}$ & $\begin{array}{l}\text { Chaves et al. (2003); Godefroid et al. } \\
\text { (2004); Gomes \& Chaves (2006); Santos } \\
\text { (2006); Carniel (2008); Schwarz-Junior } \\
\text { (2009); Santos et al. (2016) }\end{array}$ \\
\hline $\begin{array}{l}\text { Cynoscion microlepidotus } \\
\text { (Cuvier, 1830) }\end{array}$ & $\mathrm{Br}$ & food* & high & - & $\mathrm{LC}$ & $\begin{array}{l}\text { Godefroid et al. (2004); Gomes \& Chaves } \\
\text { (2006); Santos (2006); Schwarz-Junior } \\
\text { (2009); Santos et al. (2016) }\end{array}$ \\
\hline Cynoscion striatus (Cuvier, 1829) & SSWA & food* & $\begin{array}{l}\text { moderate to } \\
\text { high }\end{array}$ & - & $\mathrm{NE}$ & Carniel (2008) \\
\hline $\begin{array}{l}\text { Cynoscion virescens (Cuvier, } \\
1830 \text { ) }\end{array}$ & $\mathrm{Ca}+\mathrm{Br}$ & food* & high & - & $\mathrm{LC}$ & $\begin{array}{l}\text { Gomes \& Chaves (2006); Santos (2006); } \\
\text { Carniel (2008); Schwarz-Junior (2009); } \\
\text { Santos et al. (2016) }\end{array}$ \\
\hline $\begin{array}{l}\text { Isopisthus parvipinnis (Cuvier, } \\
1830 \text { ) }\end{array}$ & $\mathrm{Ca}+\mathrm{Br}$ & food* & low & - & $\mathrm{LC}$ & $\begin{array}{l}\text { Chaves et al. (2003); Godefroid et al. } \\
\text { (2004); Gomes \& Chaves (2006); Santos } \\
\text { (2006); Carniel (2008); Schwarz-Junior } \\
\text { (2009); Santos et al. (2016) }\end{array}$ \\
\hline Larimus breviceps Cuvier, 1830 & $\mathrm{Ca}+\mathrm{Br}$ & food* & low to moderate & - & $\mathrm{LC}$ & $\begin{array}{l}\text { Chaves et al. (2003); Godefroid et al. } \\
\text { (2004); Gomes \& Chaves (2006); Santos } \\
\text { (2006); Felix et al. (2007); Carniel (2008); } \\
\text { Schwarz-Junior (2009); Santos et al. } \\
(2016)\end{array}$ \\
\hline
\end{tabular}


Spier, D. et al.

Table 2. Continued...

\begin{tabular}{|c|c|c|c|c|c|c|}
\hline Orders/Families/Species & $\begin{array}{l}\text { Geographic } \\
\text { Distribution }\end{array}$ & $\begin{array}{c}\text { Economic } \\
\text { Importance }\end{array}$ & $\begin{array}{l}\text { Vulnerability } \\
\text { FishBase }\end{array}$ & $\begin{array}{c}\text { Conservation } \\
\text { status } \\
\text { MMA }-445\end{array}$ & $\begin{array}{c}\text { Conservation } \\
\text { status } \\
\text { IUCN }\end{array}$ & Source \\
\hline $\begin{array}{l}\text { Macrodon ancylodon (Bloch \& } \\
\text { Schneider 1801) }\end{array}$ & WA & food* & moderate & - & $\mathrm{LC}$ & $\begin{array}{l}\text { Chaves et al. (2003); Godefroid et al. } \\
\text { (2004); Santos (2006); Carniel (2008); } \\
\text { Schwarz-Junior (2009); Santos et al. } \\
\text { (2016) }\end{array}$ \\
\hline $\begin{array}{l}\text { Menticirrhus americanus } \\
\text { (Linnaeus, 1758) }\end{array}$ & WA & aquarium / food* & high & DD & LC & $\begin{array}{l}\text { Chaves et al. (2003); Godefroid et al. } \\
\text { (2004); Gomes \& Chaves (2006); Santos } \\
\text { (2006); Felix et al. (2007); Carniel } \\
\text { (2008); Schwarz-Junior (2009); Rossi- } \\
\text { Wongtschowski et al. (2014); Santos et al. } \\
(2016)\end{array}$ \\
\hline $\begin{array}{l}\text { Menticirrhus littoralis (Holbrook, } \\
\text { 1847) }\end{array}$ & WA & food* & low to moderate & DD & LC & $\begin{array}{l}\text { Godefroid et al. (2004); Gomes \& Chaves } \\
\text { (2006); Santos (2006); Felix et al. (2007); } \\
\text { Carniel (2008); Santos et al. (2016) }\end{array}$ \\
\hline $\begin{array}{l}\text { Micropogonias furnieri } \\
\text { (Desmarest, 1823) }\end{array}$ & $\mathrm{SWA}+\mathrm{Ca}$ & food* & moderate & - & LC & $\begin{array}{l}\text { Chaves et al. (2003); Gomes \& Chaves } \\
\text { (2006); Santos (2006); Felix et al. (2007); } \\
\text { Carniel (2008); Schwarz-Junior (2009); } \\
\text { Rossi-Wongtschowski et al. (2014); } \\
\text { Santos et al. (2016); Spier (2016) }\end{array}$ \\
\hline Nebris microps Cuvier, 1830 & $\mathrm{Br}$ & food* & moderate & - & LC & $\begin{array}{l}\text { Chaves et al. (2003); Godefroid et al. } \\
\text { (2004); Gomes \& Chaves (2006); Santos } \\
\text { (2006); Carniel (2008); Schwarz-Junior } \\
\text { (2009); Santos et al. (2016) }\end{array}$ \\
\hline $\begin{array}{l}\text { Odontoscion dentex (Cuvier, } \\
1830 \text { ) }\end{array}$ & WA & aquarium* & low & - & LC & $\begin{array}{l}\text { Hackradt \& Hackradt (2009); } \\
\text { Hackradt et al. (2011); Daros et al. (2012); } \\
\text { Spier (2016) }\end{array}$ \\
\hline $\begin{array}{l}\text { Ophioscion punctatissimus Meek } \\
\text { \& Hildebrand, } 1925\end{array}$ & $\mathrm{Ca}+\mathrm{Br}$ & food* & low to moderate & DD & LC & $\begin{array}{l}\text { Chaves et al. (2003); Godefroid et al. } \\
\text { (2004); Gomes \& Chaves (2006); } \\
\text { Felix et al. (2007); Schwarz-Junior (2009); } \\
\text { Santos et al. (2016) }\end{array}$ \\
\hline $\begin{array}{l}\text { Paralonchurus brasiliensis } \\
\text { (Steindachner, 1875) }\end{array}$ & $\mathrm{SWA}+\mathrm{Ca}$ & aquarium & low & - & $\mathrm{LC}$ & $\begin{array}{l}\text { Corrêa et al. (1986); Chaves et al. (2003); } \\
\text { Godefroid et al. (2004); Gomes \& Chaves } \\
\text { (2006); Santos (2006); Felix et al. (2007); } \\
\text { Carniel (2008); Schwarz-Junior (2009); } \\
\text { Santos et al. (2016) }\end{array}$ \\
\hline $\begin{array}{l}\text { Pareques acuminatus (Bloch \& } \\
\text { Schneider, 1801) }\end{array}$ & WA & aquarium & low & DD & LC & $\begin{array}{l}\text { Hackradt \& Hackradt (2009); } \\
\text { Hackradt et al. (2011); Daros et al. (2012); } \\
\text { Spier (2016) }\end{array}$ \\
\hline $\begin{array}{l}\text { Pogonias cromis (Linnaeus, } \\
1766 \text { ) }\end{array}$ & WA & food* & high & EN & LC & $\begin{array}{l}\text { Godefroid et al. (2004); Santos (2006); } \\
\text { Santos et al. (2016) }\end{array}$ \\
\hline $\begin{array}{l}\text { Stellifer brasiliensis (Schultz, } \\
1945)\end{array}$ & $\mathrm{Br}$ & animal feed & low & - & $\mathrm{NE}$ & $\begin{array}{l}\text { Chaves et al. (2003); Godefroid et al. } \\
\text { (2004); Gomes \& Chaves (2006); Santos } \\
\text { (2006); Carniel (2008); Schwarz-Junior } \\
\text { (2009); Santos et al. (2016) }\end{array}$ \\
\hline Stellifer rastrifer (Jordan, 1889) & $\mathrm{SSWA}+\mathrm{Br}$ & animal feed & low & - & LC & $\begin{array}{l}\text { Chaves et al. (2003); Godefroid et al. } \\
\text { (2004); Gomes \& Chaves (2006); Santos } \\
\text { (2006); Felix et al. (2007); Carniel (2008); } \\
\text { Schwarz-Junior (2009); Santos et al. } \\
(2016)\end{array}$ \\
\hline Stellifer stellifer (Bloch, 1790) & $\mathrm{Br}$ & animal feed & low & - & DD & $\begin{array}{l}\text { Chaves et al. (2003); Godefroid et al. } \\
\text { (2004); Gomes \& Chaves (2006); } \\
\text { Carniel (2008); Schwarz-Junior (2009); } \\
\text { Santos et al. (2016) }\end{array}$ \\
\hline Umbrina canosai Berg, 1895 & SSWA & food* & low to moderate & - & $\mathrm{NE}$ & Godefroid et al. (2004) \\
\hline Umbrina coroides Cuvier, 1830 & WA & food* & low & - & LC & $\begin{array}{l}\text { Felix et al. (2007); Schwarz Junior (2009); } \\
\text { Santos et al. (2016) }\end{array}$ \\
\hline \multicolumn{7}{|l|}{ Polynemidae } \\
\hline $\begin{array}{l}\text { Polydactylus oligodon (Günther, } \\
1860 \text { ) }\end{array}$ & WA & food* & low & - & $\mathrm{LC}$ & $\begin{array}{l}\text { Godefroid et al. (2004); Schwarz Junior } \\
\text { (2009); Santos et al. (2016) }\end{array}$ \\
\hline
\end{tabular}


Table 2. Continued...

\begin{tabular}{|c|c|c|c|c|c|c|}
\hline Orders/Families/Species & $\begin{array}{l}\text { Geographic } \\
\text { Distribution }\end{array}$ & $\begin{array}{l}\text { Economic } \\
\text { Importance }\end{array}$ & $\begin{array}{l}\text { Vulnerability } \\
\text { FishBase }\end{array}$ & $\begin{array}{l}\text { Conservation } \\
\text { status } \\
\text { MMA-445 }\end{array}$ & $\begin{array}{l}\text { Conservation } \\
\text { status } \\
\text { IUCN }\end{array}$ & Source \\
\hline $\begin{array}{l}\text { Polydactylus virginicus } \\
\text { (Linnaeus, 1758) }\end{array}$ & WA & food* & low & - & $\mathrm{LC}$ & $\begin{array}{l}\text { Chaves et al. (2003); Godefroid et al. } \\
\text { (2004); Felix et al. (2007); Carniel (2008); } \\
\text { Schwarz-Junior (2009); Santos et al. } \\
\text { (2016); Spier (2016) }\end{array}$ \\
\hline \multicolumn{7}{|l|}{ Mullidae } \\
\hline $\begin{array}{l}\text { Mullus argentinae Hubbs \& } \\
\text { Marini, } 1933\end{array}$ & SSWA & aquarium & low & - & $\mathrm{NE}$ & $\begin{array}{l}\text { Santos (2006); Schwarz Junior (2009); } \\
\text { Santos et al. (2016) }\end{array}$ \\
\hline $\begin{array}{l}\text { Pseudupeneus maculatus } \\
\text { (Bloch, 1793) }\end{array}$ & WA & food* & moderate & - & $\mathrm{LC}$ & $\begin{array}{l}\text { Hackradt \& Hackradt (2009); } \\
\text { Hackradt et al. (2011); Daros et al. (2012); } \\
\text { Spier (2016) }\end{array}$ \\
\hline \multicolumn{7}{|l|}{ Mugilidae } \\
\hline $\begin{array}{l}\text { Mugil curema Valenciennes, } \\
1836\end{array}$ & $\mathrm{TA}+\mathrm{EP}$ & food* & high & $\mathrm{DD}$ & $\mathrm{LC}$ & $\begin{array}{l}\text { Corrêa et al. (1986); Carniel (2008); Spier } \\
\text { (2016) }\end{array}$ \\
\hline Mugil liza Valenciennes, 1836 & WA & food* & moderate & NT & $\mathrm{DD}$ & Carniel (2008); Spier (2016) \\
\hline \multicolumn{7}{|l|}{ Pomacentridae } \\
\hline $\begin{array}{l}\text { Abudefduf saxatilis (Linnaeus, } \\
\text { 1758) }\end{array}$ & TA & aquarium & low to moderate & - & $\mathrm{LC}$ & $\begin{array}{l}\text { Corrêa et al. (1986); Hackradt \& Hackradt } \\
\text { (2009); Hackradt et al. (2011); Daros et al. } \\
\text { (2012); Spier (2016) }\end{array}$ \\
\hline $\begin{array}{l}\text { Chromis multilineata } \\
\text { (Guichenot, 1853) }\end{array}$ & TA & aquarium & low & - & $\mathrm{LC}$ & $\begin{array}{l}\text { Hackradt \& Hackradt (2009); } \\
\text { Hackradt et al. (2011); Daros et al. (2012); } \\
\text { Spier (2016) }\end{array}$ \\
\hline Stegastes fuscus (Cuvier, 1830) & $\mathrm{Br}$ & aquarium & low & - & $\mathrm{LC}$ & $\begin{array}{l}\text { Hackradt \& Hackradt (2009); } \\
\text { Hackradt et al. (2011); Daros et al. (2012); } \\
\text { Spier (2016) }\end{array}$ \\
\hline $\begin{array}{l}\text { Stegastes pictus (Castelnau, } \\
1855 \text { ) }\end{array}$ & $\mathrm{Ca}+\mathrm{Br}$ & aquarium & low & - & NE & Daros et al. (2012) \\
\hline $\begin{array}{l}\text { Stegastes variabilis (Castelnau, } \\
1855)\end{array}$ & WA & aquarium & low & - & $\mathrm{NE}$ & $\begin{array}{l}\text { Hackradt \& Hackradt (2009); } \\
\text { Hackradt et al. (2011); Daros et al. (2012); } \\
\text { Spier (2016) }\end{array}$ \\
\hline \multicolumn{7}{|l|}{ Uranoscopidae } \\
\hline $\begin{array}{l}\text { Astroscopus y-graecum (Cuvier, } \\
\text { 1829) }\end{array}$ & WA & food* & high & - & $\mathrm{LC}$ & $\begin{array}{l}\text { Santos (2006); Felix et al. (2007); Schwarz } \\
\text { Junior (2009); Santos et al. (2016) }\end{array}$ \\
\hline \multicolumn{7}{|l|}{ Pinguipedidae } \\
\hline $\begin{array}{l}\text { Pseudopercis semifasciata } \\
\text { (Cuvier, 1829) }\end{array}$ & SSWA & food & high & DD & $\mathrm{NE}$ & Godefroid et al. (2004) \\
\hline \multicolumn{7}{|l|}{ Blenniidae } \\
\hline $\begin{array}{l}\text { Hypleurochilus fissicornis } \\
\text { (Quoy \& Gaimard, 1824) }\end{array}$ & $\mathrm{SSWA}+\mathrm{Br}$ & No & low & - & $\mathrm{LC}$ & $\begin{array}{l}\text { Schwarz Junior (2009); Santos et al. } \\
\text { (2016); Spier (2016) }\end{array}$ \\
\hline $\begin{array}{l}\text { Hypsoblennius invemar } \text { Smith- } \\
\text { Vaniz \& Acero P., } 1980\end{array}$ & WA & aquarium & low & - & LC & $\begin{array}{l}\text { Hackradt \& Hackradt (2009); } \\
\text { Hackradt et al. (2011); Daros et al. (2012) }\end{array}$ \\
\hline $\begin{array}{l}\text { Ophioblennius trinitatis } \\
\text { Miranda Ribeiro, } 1919\end{array}$ & $\mathrm{Br}$ & aquarium & low & - & $\mathrm{LC}$ & Daros et al. (2012) \\
\hline $\begin{array}{l}\text { Parablennius marmoreus (Poey, } \\
\text { 1876) }\end{array}$ & WA & aquarium & low & - & LC & $\begin{array}{l}\text { Hackradt \& Hackradt (2009); } \\
\text { Hackradt et al. (2011); Daros et al. (2012); } \\
\text { Spier (2016) }\end{array}$ \\
\hline $\begin{array}{l}\text { Parablennius pilicornis } \\
\text { (Cuvier, 1829) }\end{array}$ & TA & aquarium & low & - & $\mathrm{LC}$ & $\begin{array}{l}\text { Hackradt \& Hackradt (2009); } \\
\text { Hackradt et al. (2011); Daros et al. (2012); } \\
\text { Spier (2016) }\end{array}$ \\
\hline $\begin{array}{l}\text { Scartella cristata (Linnaeus, } \\
1758 \text { ) }\end{array}$ & $\mathrm{CT}$ & aquarium & low & - & $\mathrm{LC}$ & $\begin{array}{l}\text { Hackradt \& Hackradt (2009); Daros et al. } \\
\text { (2012); Spier (2016) }\end{array}$ \\
\hline \multicolumn{7}{|l|}{ Gobiidae } \\
\hline $\begin{array}{l}\text { Bathygobius soporator } \\
\text { (Valenciennes, 1837) }\end{array}$ & TA & aquarium & low to moderate & - & $\mathrm{LC}$ & $\begin{array}{l}\text { Corrêa et al. (1986); Carniel (2008); } \\
\text { Hackradt \& Hackradt (2009) }\end{array}$ \\
\hline $\begin{array}{l}\text { Coryphopterus glaucofraenum } \\
\text { Gill, } 1863\end{array}$ & WA & aquarium & low & - & $\mathrm{LC}$ & $\begin{array}{l}\text { Hackradt \& Hackradt (2009); } \\
\text { Hackradt et al. (2011); Daros et al. (2012); } \\
\text { Spier (2016) }\end{array}$ \\
\hline $\begin{array}{l}\text { Microgobius meeki Evermann } \\
\& \text { Marsh, } 1899\end{array}$ & $\mathrm{Ca}+\mathrm{Br}$ & No & low & - & LC & Santos (2006); Santos et al. (2016) \\
\hline Ephippidae & & & & & & \\
\hline
\end{tabular}


Spier, D. et al.

Table 2. Continued...

\begin{tabular}{|c|c|c|c|c|c|c|}
\hline Orders/Families/Species & $\begin{array}{l}\text { Geographic } \\
\text { Distribution }\end{array}$ & $\begin{array}{l}\text { Economic } \\
\text { Importance }\end{array}$ & $\begin{array}{l}\text { Vulnerability } \\
\text { FishBase }\end{array}$ & $\begin{array}{c}\text { Conservation } \\
\text { status } \\
\text { MMA - } 445 \\
\end{array}$ & $\begin{array}{c}\text { Conservation } \\
\text { status } \\
\text { IUCN } \\
\end{array}$ & Source \\
\hline $\begin{array}{l}\text { Chaetodipterus faber } \\
\text { (Broussonet, 1782) }\end{array}$ & WA & aquarium / food* & high & - & $\mathrm{LC}$ & $\begin{array}{l}\text { Chaves et al. (2003); Godefroid et al. } \\
\text { (2004); Gomes \& Chaves (2006); Santos } \\
\text { (2006); Felix et al. (2007); Carniel } \\
\text { (2008); Hackradt \& Hackradt (2009); } \\
\text { Schwarz-Junior (2009); Hackradt et al. } \\
\text { (2011); Daros et al. (2012); Rossi- } \\
\text { Wongtschowski et al. (2014); Santos et al. } \\
\text { (2016); Spier (2016) }\end{array}$ \\
\hline
\end{tabular}

\section{Acanthuridae}

$\begin{array}{lllll}\text { Acanthurus bahianus Castelnau, } & \text { WA } & \text { aquarium } & \text { low to moderate } & -\end{array}$
1855

\begin{tabular}{llllll}
\hline $\begin{array}{l}\text { Acanthurus chirurgus (Bloch, } \\
\text { 1787) }\end{array}$ & TA & aquarium & low & LC
\end{tabular}

\begin{tabular}{llllll}
\hline $\begin{array}{l}\text { Acanthurus chirurgus (Bloch, } \\
\text { 1787) }\end{array}$ & TA & aquarium & low & LC
\end{tabular}

LC

Corrêa et al. (1986); Hackradt \& Hackradt (2009); Hackradt et al. (2011); Daros et al. (2012)

-

\begin{tabular}{lcccc}
\hline $\begin{array}{l}\text { Acanthurus coeruleus Bloch \& } \\
\text { Schneider, 1801 }\end{array}$ & WA & aquarium & high & LC \\
\hline Sphyraenidae & & & & \\
\hline $\begin{array}{l}\text { Sphyraena barracuda } \\
\text { (Edwards, 1771) }\end{array}$ & TA & food* & very high & - \\
\hline $\begin{array}{l}\text { Sphyraena guachancho Cuvier, } \\
1829\end{array}$ & TA & food* & very high & LC \\
\end{tabular}

Hackradt \& Hackradt (2009);

Hackradt et al. (2011); Daros et al. (2012); Spier (2016)

Daros et al. (2012); Spier (2016)

$\begin{array}{llllll}\text { Sphyraena picudilla Poey, } 1860 & \text { WA } & \text { food* }^{*} & \begin{array}{c}\text { moderate to } \\ \text { high }\end{array} & \text { DD } & \text { NE } \\ \text { Sphyraena tome Fowler, 1903 } & \text { SSWA } & \text { food* } & \text { low to moderate } & \text { DD } & \text { NE }\end{array}$

\begin{tabular}{|c|c|c|c|c|c|c|}
\hline \multirow{2}{*}{\multicolumn{7}{|c|}{ Gempylidae }} \\
\hline & & & & & & \\
\hline $\begin{array}{l}\text { Thyrsitops lepidopoides } \\
\text { (Cuvier, 1832) }\end{array}$ & SSWA & food* & moderate & - & $\mathrm{NE}$ & Rossi-Wongtschowski et al. (2014) \\
\hline \multicolumn{7}{|l|}{ Trichiuridae } \\
\hline $\begin{array}{l}\text { Trichiurus lepturus Linnaeus, } \\
1758\end{array}$ & CT & food* & high & - & $\mathrm{LC}$ & $\begin{array}{l}\text { Chaves et al. (2003); Godefroid et al. } \\
\text { (2004); Gomes \& Chaves (2006); Santos } \\
\text { (2006); Felix et al. (2007); Carniel } \\
\text { (2008); Schwarz-Junior (2009); Rossi- } \\
\text { Wongtschowski et al. (2014); Santos et al. } \\
\text { (2016); Spier (2016) }\end{array}$ \\
\hline \multicolumn{7}{|l|}{ Scombridae } \\
\hline Scomber colias Gmelin, 1789 & $\mathrm{Ta}$ & food* & moderate & - & $\mathrm{LC}$ & Rossi-Wongtschowski et al. (2014) \\
\hline $\begin{array}{l}\text { Scomberomorus brasiliensis } \\
\text { Collette, Russo \& Zavala- } \\
\text { Camin, } 1978\end{array}$ & WA & food* & $\begin{array}{l}\text { high to very } \\
\text { high }\end{array}$ & - & $\mathrm{LC}$ & $\begin{array}{l}\text { Felix et al. (2007); Hackradt \& Hackradt } \\
\text { (2009); Hackradt et al. (2011); Daros et al. } \\
\text { (2012); Rossi-Wongtschowski et al. } \\
\text { (2014); Spier (2016) }\end{array}$ \\
\hline $\begin{array}{l}\text { Scomberomorus cavalla } \\
\text { (Cuvier, 1829) }\end{array}$ & WA & food* & $\begin{array}{l}\text { high to very } \\
\text { high }\end{array}$ & - & $\mathrm{LC}$ & $\begin{array}{l}\text { Carniel (2008); Hackradt \& Hackradt } \\
\text { (2009); Hackradt et al. (2011); Spier } \\
(2016)\end{array}$ \\
\hline \multicolumn{7}{|l|}{ Stromateidae } \\
\hline Peprilus paru (Linnaeus, 1758) & WA & food* & low to moderate & - & $\mathrm{LC}$ & $\begin{array}{l}\text { Chaves et al. (2003); Godefroid et al. } \\
\text { (2004); Gomes \& Chaves (2006); Santos } \\
\text { (2006); Carniel (2008); Schwarz-Junior } \\
\text { (2009); Rossi-Wongtschowski et al. } \\
\text { (2014); Santos et al. (2016); Spier (2016) }\end{array}$ \\
\hline
\end{tabular}

Hackradt \& Hackradt (2009); Santos et al. (2016)

\section{Pempheridae}


Table 2. Continued...

\begin{tabular}{|c|c|c|c|c|c|c|}
\hline Orders/Families/Species & $\begin{array}{l}\text { Geographic } \\
\text { Distribution }\end{array}$ & $\begin{array}{c}\text { Economic } \\
\text { Importance }\end{array}$ & $\begin{array}{l}\text { Vulnerability } \\
\text { FishBase }\end{array}$ & $\begin{array}{c}\text { Conservation } \\
\text { status } \\
\text { MMA - } 445\end{array}$ & $\begin{array}{c}\text { Conservation } \\
\text { status } \\
\text { IUCN } \\
\end{array}$ & Source \\
\hline $\begin{array}{l}\text { Pempheris schomburgkii Müller } \\
\text { \& Troschel, } 1848\end{array}$ & WA & aquarium & low & - & $\mathrm{LC}$ & $\begin{array}{l}\text { Hackradt \& Hackradt (2009); } \\
\text { Hackradt et al. (2011); Daros et al. (2012); } \\
\text { Spier (2016) }\end{array}$ \\
\hline \multicolumn{7}{|l|}{ Chaetodontidae } \\
\hline $\begin{array}{l}\text { Chaetodon striatus Linnaeus, } \\
1758\end{array}$ & WA & aquarium & low & - & $\mathrm{LC}$ & $\begin{array}{l}\text { Hackradt \& Hackradt (2009); } \\
\text { Hackradt et al. (2011); Daros et al. (2012); } \\
\text { Spier (2016) }\end{array}$ \\
\hline \multicolumn{7}{|l|}{ Pomacanthidae } \\
\hline $\begin{array}{l}\text { Pomacanthus paru (Bloch, } \\
\text { 1787) }\end{array}$ & WA & aquarium & moderate & DD & $\mathrm{LC}$ & $\begin{array}{l}\text { Hackradt \& Hackradt (2009); } \\
\text { Hackradt et al. (2011); Daros et al. (2012); } \\
\text { Spier (2016) }\end{array}$ \\
\hline \multicolumn{7}{|l|}{ Labridae } \\
\hline $\begin{array}{l}\text { Bodianus rufus (Linnaeus, } \\
\text { 1758) }\end{array}$ & WA & aquarium & low & - & $\mathrm{LC}$ & Daros et al. (2012); Spier (2016) \\
\hline $\begin{array}{l}\text { Halichoeres brasiliensis (Bloch, } \\
\text { 1791) }\end{array}$ & SWA & aquarium & $\begin{array}{l}\text { moderate to } \\
\text { high }\end{array}$ & - & DD & Spier (2016) \\
\hline $\begin{array}{l}\text { Halichoeres poeyi } \\
\text { (Steindachner, 1867) }\end{array}$ & WA & aquarium & low & - & $\mathrm{LC}$ & $\begin{array}{l}\text { Hackradt \& Hackradt (2009); } \\
\text { Hackradt et al. (2011); Daros et al. (2012); } \\
\text { Spier (2016) }\end{array}$ \\
\hline \multicolumn{7}{|l|}{ Scaridae } \\
\hline $\begin{array}{l}\text { Sparisoma amplum (Ranzani, } \\
1841 \text { ) }\end{array}$ & $\mathrm{Br}$ & aquarium & moderate & NT & $\mathrm{LC}$ & $\begin{array}{l}\text { Hackradt \& Hackradt (2009); } \\
\text { Hackradt et al. (2011); Daros et al. (2012) }\end{array}$ \\
\hline $\begin{array}{l}\text { Sparisoma axillare } \\
\text { (Steindachner, 1878) }\end{array}$ & $\mathrm{Br}$ & aquarium & moderate & $\mathrm{VU}$ & DD & $\begin{array}{l}\text { Hackradt \& Hackradt (2009); } \\
\text { Hackradt et al. (2011); Daros et al. (2012); } \\
\text { Spier (2016) }\end{array}$ \\
\hline $\begin{array}{l}\text { Sparisoma frondosum (Agassiz, } \\
1831 \text { ) }\end{array}$ & $\mathrm{Ca}+\mathrm{Br}$ & aquarium & low to moderate & $\mathrm{VU}$ & DD & $\begin{array}{l}\text { Hackradt \& Hackradt (2009); } \\
\text { Hackradt et al. (2011); Daros et al. (2012); } \\
\text { Spier (2016) }\end{array}$ \\
\hline $\begin{array}{l}\text { Sparisoma radians } \\
\text { (Valenciennes, 1840) }\end{array}$ & WA & aquarium & low & - & $\mathrm{LC}$ & $\begin{array}{l}\text { Hackradt \& Hackradt (2009); Daros et al. } \\
\text { (2012) }\end{array}$ \\
\hline \multicolumn{7}{|l|}{ Labrisomidae } \\
\hline $\begin{array}{l}\text { Labrisomus nuchipinnis (Quoy } \\
\text { \& Gaimard, 1824) }\end{array}$ & TA & aquarium & low & - & $\mathrm{LC}$ & $\begin{array}{l}\text { Hackradt \& Hackradt (2009); } \\
\text { Hackradt et al. (2011); Daros et al. (2012); } \\
\text { Spier (2016) }\end{array}$ \\
\hline $\begin{array}{l}\text { Malacoctenus delalandii } \\
\text { (Valenciennes, 1836) }\end{array}$ & WA & No & low & - & $\mathrm{LC}$ & $\begin{array}{l}\text { Hackradt \& Hackradt (2009); } \\
\text { Hackradt et al. (2011); Daros et al. (2012); } \\
\text { Spier (2016) }\end{array}$ \\
\hline $\begin{array}{l}\text { Paraclinus spectator Guimarães } \\
\text { \& Bacellar, } 2002\end{array}$ & $\mathrm{Br}$ & No & low & - & $\mathrm{LC}$ & Daros et al. (2012) \\
\hline \multicolumn{7}{|l|}{ Pleuronectiformes } \\
\hline \multicolumn{7}{|l|}{ Paralichthyidae } \\
\hline $\begin{array}{l}\text { Citharichthys arenaceus } \\
\text { Evermann \& Marsh, } 1900\end{array}$ & WA & animal feed & low & - & $\mathrm{LC}$ & $\begin{array}{l}\text { Chaves et al. (2003); Gomes \& Chaves } \\
\text { (2006); Santos (2006); Felix et al. (2007); } \\
\text { Carniel (2008); Schwarz-Junior (2009); } \\
\text { Santos et al. (2016) }\end{array}$ \\
\hline $\begin{array}{l}\text { Citharichthys macrops Dresel, } \\
1885\end{array}$ & WA & animal feed & low & - & $\mathrm{LC}$ & $\begin{array}{l}\text { Santos (2006); Felix et al. (2007); } \\
\text { Schwarz-Junior (2009); Santos et al. } \\
(2016)\end{array}$ \\
\hline $\begin{array}{l}\text { Citharichthys spilopterus } \\
\text { Günther, } 1862\end{array}$ & WA & animal feed & low & - & $\mathrm{LC}$ & $\begin{array}{l}\text { Chaves et al. (2003); Godefroid et al. } \\
\text { (2004); Gomes \& Chaves (2006); } \\
\text { Santos (2006); Schwarz-Junior (2009); } \\
\text { Santos et al. (2016) }\end{array}$ \\
\hline $\begin{array}{l}\text { Etropus crossotus Jordan \& } \\
\text { Gilbert, } 1882\end{array}$ & $\mathrm{WA}+\mathrm{EP}$ & animal feed & low & - & $\mathrm{LC}$ & $\begin{array}{l}\text { Chaves et al. (2003); Godefroid et al. } \\
\text { (2004); Gomes \& Chaves (2006); Santos } \\
\text { (2006); Felix et al. (2007); Carniel (2008); } \\
\text { Schwarz-Junior (2009); Santos et al. } \\
\text { (2016) }\end{array}$ \\
\hline $\begin{array}{l}\text { Paralichthys brasiliensis } \\
\text { (Ranzani, 1842) }\end{array}$ & SWA & food & $\begin{array}{l}\text { moderate to } \\
\text { high }\end{array}$ & - & $\mathrm{NE}$ & Godefroid et al. (2004) \\
\hline $\begin{array}{l}\text { Paralichthys orbignyanus } \\
\text { (Valenciennes, 1839) }\end{array}$ & SSWA & food & $\begin{array}{l}\text { moderate to } \\
\text { high }\end{array}$ & DD & $\mathrm{NE}$ & Carniel (2008) \\
\hline
\end{tabular}


Spier, D. et al.

Table 2. Continued..

\begin{tabular}{|c|c|c|c|c|c|c|}
\hline Orders/Families/Species & $\begin{array}{l}\text { Geographic } \\
\text { Distribution }\end{array}$ & $\begin{array}{c}\text { Economic } \\
\text { Importance }\end{array}$ & $\begin{array}{l}\text { Vulnerability } \\
\text { FishBase }\end{array}$ & $\begin{array}{c}\text { Conservation } \\
\text { status } \\
\text { MMA - } 445 \\
\end{array}$ & $\begin{array}{c}\text { Conservation } \\
\text { status } \\
\text { IUCN } \\
\end{array}$ & Source \\
\hline $\begin{array}{l}\text { Paralichthys patagonicus } \\
\text { Jordan, } 1889\end{array}$ & $\mathrm{SSWA}+\mathrm{EP}$ & food & low to moderate & NT & $\mathrm{NE}$ & Santos (2006); Santos et al. (2016) \\
\hline $\begin{array}{l}\text { Syacium micrurum Ranzani, } \\
1842\end{array}$ & $\mathrm{Ca}+\mathrm{Br}$ & food & moderate & - & $\mathrm{LC}$ & $\begin{array}{l}\text { Schwarz Junior (2009); Santos et al. } \\
(2016)\end{array}$ \\
\hline $\begin{array}{l}\text { Syacium papillosum (Linnaeus, } \\
1758 \text { ) }\end{array}$ & WA & animal feed & low to moderate & - & $\mathrm{LC}$ & $\begin{array}{l}\text { Chaves et al. (2003); Santos (2006); } \\
\text { Felix et al. (2007); Carniel (2008); } \\
\text { Schwarz-Junior (2009); Santos et al. } \\
(2016)\end{array}$ \\
\hline \multicolumn{7}{|l|}{ Bothidae } \\
\hline $\begin{array}{l}\text { Bothus robinsi Topp \& Hoff, } \\
1972\end{array}$ & WA & animal feed & low to moderate & - & $\mathrm{LC}$ & Chaves et al. (2003) \\
\hline \multicolumn{7}{|l|}{ Pleuronectidae } \\
\hline $\begin{array}{l}\text { Oncopterus darwinii } \\
\text { Steindachner, } 1874\end{array}$ & SSWA & animal feed & moderate & - & $\mathrm{NE}$ & $\begin{array}{l}\text { Godefroid et al. (2004); Santos (2006); } \\
\text { Felix et al. (2007); Santos et al. (2016) }\end{array}$ \\
\hline \multicolumn{7}{|l|}{ Achiridae } \\
\hline $\begin{array}{l}\text { Achirus declivis Chabanaud, } \\
1940\end{array}$ & WA & animal feed & low & - & $\mathrm{LC}$ & $\begin{array}{l}\text { Gomes \& Chaves (2006); Santos (2006); } \\
\text { Schwarz-Junior (2009); Santos et al. } \\
(2016)\end{array}$ \\
\hline $\begin{array}{l}\text { Achirus lineatus (Linnaeus, } \\
\text { 1758) }\end{array}$ & WA & aquarium & low to moderate & - & $\mathrm{LC}$ & $\begin{array}{l}\text { Chaves et al. (2003); Godefroid et al. } \\
\text { (2004); Gomes \& Chaves (2006); } \\
\text { Santos (2006); Schwarz-Junior (2009); } \\
\text { Santos et al. (2016) }\end{array}$ \\
\hline $\begin{array}{l}\text { Trinectes microphthalmus } \\
\text { (Chabanaud, 1928) }\end{array}$ & $\mathrm{Ca}+\mathrm{Br}$ & animal feed & low & - & $\mathrm{LC}$ & $\begin{array}{l}\text { Chaves et al. (2003); Godefroid et al. } \\
\text { (2004); Santos (2006); Carniel (2008); } \\
\text { Schwarz-Junior (2009); Santos et al. } \\
(2016)\end{array}$ \\
\hline $\begin{array}{l}\text { Trinectes paulistanus (Miranda } \\
\text { Ribeiro, 1915) }\end{array}$ & $\mathrm{Ca}+\mathrm{Br}$ & animal feed & low & - & $\mathrm{LC}$ & $\begin{array}{l}\text { Godefroid et al. (2004); Gomes \& Chaves } \\
\text { (2006); Santos (2006); Carniel (2008); } \\
\text { Schwarz-Junior (2009); Santos et al. } \\
(2016)\end{array}$ \\
\hline \multicolumn{7}{|l|}{ Cynoglossidae } \\
\hline $\begin{array}{l}\text { Symphurus diomedeanus } \\
\text { (Goode \& Bean, 1885) }\end{array}$ & WA & animal feed & low to moderate & - & $\mathrm{LC}$ & Corrêa et al. (1986) \\
\hline $\begin{array}{l}\text { Symphurus plagusia (Bloch \& } \\
\text { Schneider, 1801) }\end{array}$ & $\mathrm{Ca}+\mathrm{Br}$ & animal feed & low to moderate & - & $\mathrm{LC}$ & Godefroid et al. (2004) \\
\hline $\begin{array}{l}\text { Symphurus tessellatus (Quoy \& } \\
\text { Gaimard, 1824) }\end{array}$ & $\mathrm{Ca}+\mathrm{SSWA}+\mathrm{Br}$ & animal feed & moderate & - & $\mathrm{LC}$ & $\begin{array}{l}\text { Chaves et al. (2003); Godefroid et al. } \\
\text { (2004); Gomes \& Chaves (2006); Santos } \\
\text { (2006); Carniel (2008); Schwarz-Junior } \\
\text { (2009); Santos et al. (2016) }\end{array}$ \\
\hline \multicolumn{7}{|l|}{ Tetraodontiformes } \\
\hline \multicolumn{7}{|l|}{ Balistidae } \\
\hline $\begin{array}{l}\text { Balistes capriscus Gmelin, } \\
1789\end{array}$ & TA & food* & low to moderate & NT & VU & $\begin{array}{l}\text { Chaves et al. (2003); Hackradt \& Hackradt } \\
\text { (2009); Hackradt et al. (2011); Rossi- } \\
\text { Wongtschowski et al. (2014); Spier (2016) }\end{array}$ \\
\hline \multicolumn{7}{|l|}{ Monacanthidae } \\
\hline $\begin{array}{l}\text { Aluterus monoceros (Linnaeus, } \\
1758 \text { ) }\end{array}$ & CT & food* & high & NT & $\mathrm{LC}$ & Hackradt \& Hackradt (2009); Spier (2016) \\
\hline $\begin{array}{l}\text { Monacanthus ciliatus (Mitchill, } \\
\text { 1818) }\end{array}$ & TA & food & low to moderate & - & $\mathrm{LC}$ & Godefroid et al. (2004) \\
\hline $\begin{array}{l}\text { Stephanolepis hispidus } \\
\text { (Linnaeus, 1766) }\end{array}$ & TA & aquarium* & low to moderate & - & $\mathrm{LC}$ & $\begin{array}{l}\text { Chaves et al. (2003); Santos (2006); } \\
\text { Felix et al. (2007); Carniel (2008); } \\
\text { Hackradt \& Hackradt (2009); } \\
\text { Schwarz-Junior (2009); Hackradt et al. } \\
\text { (2011); Daros et al. (2012); Rossi- } \\
\text { Wongtschowski et al. (2014); Santos et al. } \\
\text { (2016); Spier (2016) }\end{array}$ \\
\hline
\end{tabular}


Table 2. Continued...

\begin{tabular}{|c|c|c|c|c|c|c|}
\hline Orders/Families/Species & $\begin{array}{l}\text { Geographic } \\
\text { Distribution }\end{array}$ & $\begin{array}{l}\text { Economic } \\
\text { Importance }\end{array}$ & $\begin{array}{l}\text { Vulnerability } \\
\text { FishBase }\end{array}$ & $\begin{array}{l}\text { Conservation } \\
\text { status } \\
\text { MMA-445 }\end{array}$ & $\begin{array}{l}\text { Conservation } \\
\text { status } \\
\text { IUCN } \\
\end{array}$ & Source \\
\hline \multicolumn{7}{|l|}{ Tetraodontidae } \\
\hline $\begin{array}{l}\text { Lagocephalus laevigatus } \\
\text { (Linnaeus, 1766) }\end{array}$ & TA & aquarium* & high & - & $\mathrm{LC}$ & $\begin{array}{l}\text { Chaves et al. (2003); Godefroid et al. } \\
\text { (2004); Gomes \& Chaves (2006); Santos } \\
\text { (2006); Carniel (2008); Schwarz-Junior } \\
\text { (2009); Santos et al. (2016) }\end{array}$ \\
\hline $\begin{array}{l}\text { Sphoeroides greeleyi Gilbert, } \\
1900\end{array}$ & $\mathrm{Ca}+\mathrm{Br}$ & aquarium & low & - & LC & $\begin{array}{l}\text { Chaves et al. (2003); Godefroid et al. } \\
\text { (2004); Gomes \& Chaves (2006); Santos } \\
\text { (2006); Hackradt \& Hackradt (2009); } \\
\text { Hackradt et al. (2011); Santos et al. (2016) }\end{array}$ \\
\hline $\begin{array}{l}\text { Sphoeroides spengleri (Bloch, } \\
1785)\end{array}$ & $\mathrm{TA}$ & aquarium & low to moderate & - & LC & $\begin{array}{l}\text { Santos (2006); Hackradt \& Hackradt } \\
\text { (2009); Schwarz-Junior (2009); } \\
\text { Hackradt et al. (2011); Daros et al. (2012); } \\
\text { Santos et al. (2016); Spier (2016) }\end{array}$ \\
\hline $\begin{array}{l}\text { Sphoeroides testudineus } \\
\text { (Linnaeus, 1758) }\end{array}$ & WA & aquarium / food* & low & $\mathrm{DD}$ & $\mathrm{LC}$ & $\begin{array}{l}\text { Godefroid et al. (2004); Gomes \& } \\
\text { Chaves (2006); Santos (2006); Felix et al. } \\
\text { (2007); Carniel (2008); Hackradt \& } \\
\text { Hackradt (2009); Schwarz-Junior (2009); } \\
\text { Santos et al. (2016) }\end{array}$ \\
\hline \multicolumn{7}{|l|}{ Diodontidae } \\
\hline $\begin{array}{l}\text { Chilomycterus spinosus } \\
\text { spinosus (Linnaeus, 1758) }\end{array}$ & SWA & aquarium & low to moderate & - & $\mathrm{LC}$ & $\begin{array}{l}\text { Chaves et al. (2003); Santos (2006); } \\
\text { Felix et al. (2007); Carniel (2008); } \\
\text { Hackradt \& Hackradt (2009); Schwarz- } \\
\text { Junior (2009); Hackradt et al. (2011); } \\
\text { Rossi-Wongtschowski et al. (2014); } \\
\text { Santos et al. (2016) }\end{array}$ \\
\hline \multicolumn{7}{|l|}{ Molidae } \\
\hline $\begin{array}{l}\text { Ranzania laevis (Pennant, } \\
\text { 1776) }\end{array}$ & $\mathrm{TA}+\mathrm{EP}$ & No & $\begin{array}{l}\text { moderate to } \\
\text { high }\end{array}$ & - & $\mathrm{LC}$ & Spier (2016) \\
\hline \multicolumn{7}{|l|}{ Beryciformes } \\
\hline \multicolumn{7}{|l|}{ Holocentridae } \\
\hline $\begin{array}{l}\text { Holocentrus adscensionis } \\
\text { (Osbeck, 1765) }\end{array}$ & $\mathrm{TA}$ & aquarium & low to moderate & - & $\mathrm{LC}$ & $\begin{array}{l}\text { Hackradt \& Hackradt (2009); } \\
\text { Hackradt et al. (2011); Daros et al. (2012); } \\
\text { Spier (2016) }\end{array}$ \\
\hline \multicolumn{7}{|l|}{ Gasterosteiformes } \\
\hline \multicolumn{7}{|l|}{ Fistulariidae } \\
\hline $\begin{array}{l}\text { Fistularia tabacaria Linnaeus, } \\
1758\end{array}$ & TA & aquarium & $\begin{array}{l}\text { high to very } \\
\text { high }\end{array}$ & - & LC & $\begin{array}{l}\text { Hackradt \& Hackradt (2009); } \\
\text { Hackradt et al. (2011); Daros et al. (2012); } \\
\text { Spier (2016) }\end{array}$ \\
\hline
\end{tabular}

Cynoscion (6) and Carcharhinus (6) were the dominant genus in number of species, followed by Anchoa (5), Gymnothorax (5) and Lutjanus (5).

The geographic distribution of species across the different categories defined in the previous section are illustrated in Figure 2. Many of the recorded species are widely distributed over the Western Atlantic, and can be further separated into two groups with distinct distribution: the first, characteristic of the Caribbean fauna, is also found in the Caribbean and Brazilian Province; and the second, with temperate affinities, is characteristic of the Southern Southwest Atlantic, including Argentina and Uruguay.

In terms of Brazilian economic importance, 156 species (57\%) are used for human consumption, 74 species $(27 \%)$ for aquaria and 30 species $(11 \%)$ for animal feed. Only 19 species (7\%) have no commercial importance in Brazil. In the State of Paraná, on the other hand, only 57\% of species of economic interest in Brazil are exploited. In particular, 21 species used for human consumption in other parts of Brazil have no economic importance in Paraná. Moreover, the aquaria and animal feed industries are relatively underdeveloped, with only 9 of 74 potentially viable species used in aquaria, and 4 of 30 potentially viable species commercialized for animal feed. In short, of 253 species of economic interest in Brazil, only 144 are exploited in the State of Paraná (Figure 3).

A total of $61 \%$ of species were categorized as having low to moderate vulnerability to extinction, and 39\% ranged from moderate to very high vulnerability (Table 2). Most Elasmobranchii (29 species) were highly or very highly vulnerable. Among the Perciformes, 50 of the 146 species were classified as having moderate to very high vulnerability. Considering both red lists, $82 \%$ of catalogued species in Paraná's inner shelf were assessed for their risk of extinction. Two hundred and forty-two species occurring in the shallow inner continental shelf of Paraná appear in the red list of the International Union for Conservation of Nature (IUCN 2017), where 185 are listed as least concern, 17 as data deficient, 12 as near threatened, 17 as vulnerable, 8 as endangered, and 3 as critically endangered. The Brazilian Ministry of Environment (MMA 2014) classified substantially less species in the area ( 85 species), however with higher risk of extinction (12 vulnerable, 7 endangered, 15 critically endangered) (Figure 4). 
Spier, D. et al.

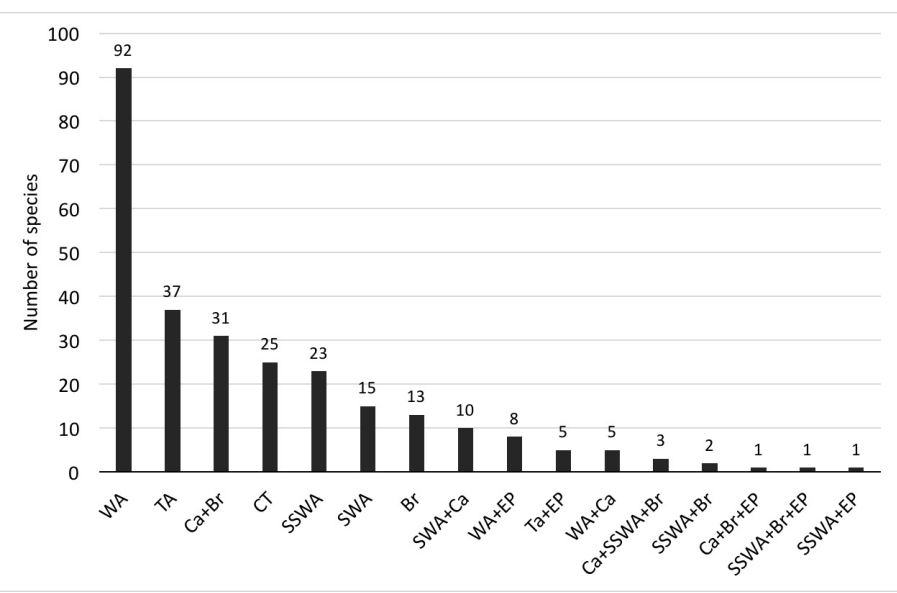

Figure 2. Geographic distribution of the species recorded in the shallow inner continental shelf of Paraná. CT $=$ Circumtropical, $\mathrm{TA}=$ Trans-Atlantic, WA = Western Atlantic, SWA $=$ Southwest Atlantic, SSWA $=$ Southern Southwest Atlantic, $\mathrm{Ca}=$ Caribbean, $\mathrm{Br}=$ Brazilian Province, $\mathrm{EP}=$ Eastern Pacific.

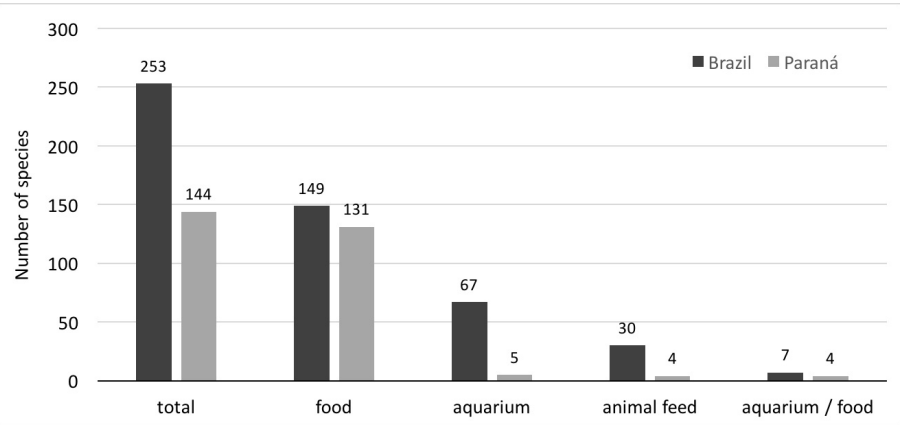

Figure 3. Number of catalogued species with economic importance in the State of Paraná only, versus the number with economic importance in Brazil overall.

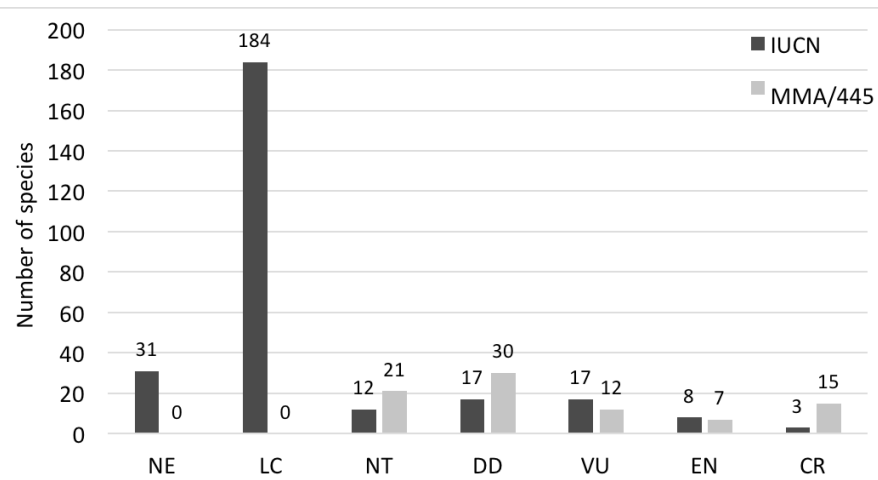

Figure 4. Global conservation status according to IUCN (2017) and National conservation status according to $\mathrm{MMA}$ (2014): $\mathrm{NE}=$ not evaluated, $\mathrm{LC}=$ least concern, $\mathrm{NT}=$ near threatened, $\mathrm{DD}=$ data deficient, $\mathrm{VU}=$ vulnerable, $\mathrm{EN}=$ endangered, $\mathrm{CR}=$ critically endangered.

\section{Discussion}

The vastness of the Brazilian coast and its large ecosystem and biodiversity contributed to a false perception of inexhaustible fishing resources, and the misguided adoption of policies that neglected resource sustainability and focused primarily on species of commercial importance (Nahum et al. 2009). A necessary step towards implementing better informed policies is to obtain an accurate assessment of species occurrence, and their respective economic importance and vulnerability to extinction. Such comprehensive assessment is still lacking for Paraná's shallow inner continental shelf, in Southern Brazil, home to several threatened species. In an attempt to remedy this situation, this study compiled the results of surveys of Paraná's shallow inner continental shelf performed over the past 30 years, providing a comprehensive checklist of fish species, along with information on biogeography, conservation status, economic importance and degree of species' vulnerability.

Extracting correlations between the various factors that could influence species vulnerability to extinction, and hence pinpointing its causes, is beyond the scope if this work. Nonetheless, we believe that our checklist provides valuable information for future studies on the ecology and conservation of the fish fauna of the area.

In our study, we have confirmed a rich fauna of Elasmobranchii in the continental shelf of Paraná, comprising 24\% of Brazilian's elasmobranch fauna (Rosa \& Gadig 2014). Several elasmobranchs that occur in Paraná seem to use the southern coast of Brazil for reproduction (Bornatowski \& Abilhoa 2012). Vooren et al. (2005) recorded 21 species that use areas on the southern continental shelf for reproduction. It is suspected that several species also use Paraná's coast as parturition and nursery grounds, such as Carcharhinus limbatus, Rhizoprionodon lalandii, Sphyrna lewini, Narcine brasiliensis, Rioraja agassizi, Pseudobatos percellens and Zapteryx brevirostris.

According to Castello (1994), the coastal fish fauna in Southeastern and Southern Brazil is composed of a mixture of species with tropical to subantarctic affinities, explaining the richness of the fish fauna in Paraná's inner shelf. Among the Actinopterygii, Sciaenidae was the most representative family in other continental shelves of Brazil (Rocha \& Rossi-Wongtschowski 1998; Muto et al. 2000; Moraes et al. 2009) and its occurrence in Paraná's inner continental shelf is associated with Coastal Water (Muto et al. 2000). Sciaenidae and Carangidae were also the most speciose families in both estuaries of the region: the PEC (Passos et al. 2012) and the Guaratuba Bay (Chaves \& Corrêa 1998; Chaves \& Vendel 2001). In Brazilian waters, there are 37 species of Sciaenidae and 25 species of Cynoscion, with 25 species of Sciaenidae and 9 of Cynoscion occurring in Paraná (Nelson et al. 2016). That means that only three species of Cynoscion do not occur, or were not registered, in the State of Paraná. Cynoscion guatucupa, for instance, is not listed in this checklist, but its range of occurrence goes from southeastern Brazil to Uruguay. The other two Cynoscion species (C. similis and C. steindachneri) only occur in the Northern Brazilian coast (Nelson et al. 2016).

Fishery activities on the coast of Paraná are mostly artisanal or small-scale commercial operations, mainly utilizing two basic types of gear, gillnets and bottom trawl-nets (IPARDES 1981; Andriguetto-Filho 2002; Chaves \& Robert 2003; Robert \& Chaves 2006; Andriguetto-Filho et al. 2009). They target different resources over the year based on seasonal changes in species abundance and tourism (Robert \& Chaves 2006). Trawling targets shrimp, Xiphopenaus kroyeri (Heller, 1862), Litopenaeus schmitti (Burkenroad 1936) and Farfantepenaeus sp. (Branco \& Verani 2006; Robert et al. 2007), while gillnetting targets mainly teleosts and elasmobranchs such as Carcharhiniformes and Rhinobatidae (Costa \& Chaves 2006; Robert \& Chaves 2006; Bornatowski \& Abilhoa 2012). A considerable number of species (109) with economic importance in Brazil are not commercialized in Paraná. These species can be considered as bycatch in the region, following Guanais et al. (2015) who define bycatch as the portion of the total catch that is effectively discarded. Sciaenidae, such as Ctenosciaena gracilicirrhus, Isopisthus parvipinnis, Larimus breviceps, Menticirrhus americanus, Paralonchurus brasiliensis, Stellifer brasiliensis and Stellifer rastrifer, although reported as shrimp bycatch in other studies (Cattani et al. 2011; Santos et al. 2016), have some economic importance in the region. 
The lack of risk assessment for $18 \%$ of the species catalogued in this study under global lists can be attributed to the lack of studies on basic biology, habitat requirement, abundance, and distribution (Lamas et al. 2016), as well as lacking fishery statistics (discontinued in 2012) (Dario et al. 2015; Barreto et al. 2017). Therefore, is imperative that fishery monitoring programs be reinstated in Brazil to allow for science-based management (Dario et al. 2015).

We conclude with a few cautionary comments. First of all, the sampling methods and sampling efforts varied across the different studies compiled in this checklist, and therefore comparisons of their results, or statistical inferences based on combined results, are not straightforward to make. Hard conclusions should not be drawn before taking such systematic differences into account. Secondly, the sampling areas also differed across studies, so it was not possible to draw conclusions regarding temporal variations of species' occurrence. Nonetheless, our results, combined with effective monitoring of fishing activities, deposition of dredged sediments, and deployment of artificial habitats, could inform policy making regarding management and administration of the fishery resources of the Brazilian continental shelf.

\section{Acknowledgements}

We are grateful to the Geological Oceanography Laboratory at the Center for Marine Studies, UFPR, for providing its map database. We are also indebted to Pâmela Emanuelly Cattani for her help with maps. The work of Daphne Spier were partially supported by a PhD's grant from the Coordination for Improvement of Higher Education Personnel (CAPESBrazil).

\section{Authors' Contributions}

Substantial contribution in the concept and design of the study: Daphne Spier, Henry Spach

Contribution to data collection: Daphne Spier, Humberto Gerum, Natalia Mattos, Hugo Bornatowski

Contribution to data analysis and interpretation: Daphne Spier, Humberto

Gerum, Riguel Contente, Hugo Bornatowski

Contribution to manuscript preparation: All authors

Contribution to critical revision, adding intelectual content: All authors

\section{Conflicts of interest}

The authors declare that they have no conflict of interest related to the publication of this manuscript.

\section{References}

ANDRIGUETTO-FILHO, J.M. 2002. Sistemas técnicos de pesca no litoral do Paraná: caracterização e tipificação. In: Desenvolvimento e meio ambiente: em busca da interdisciplinaridade. Pesquisa urbanas e rurais. C. Raynaut, M. Zanoni, P. C. Lana, D. Floriani, A. D. D. Ferreira, J. M. Andriguetto-Filho (Eds). Editora UFPR (Universidade Federal do Paraná), Curitiba, pp. 213-233.

ANDRIGUETTO, J.M., KRUL, R. \& FEITOSA, S. 2009. Analysis of natural and social dynamics of fishery production systems in Paraná, Brazil: implications for management and sustainability. J. Appl. Ichthyol. 25(3):277-286.

BARRETO, R.R., BORNATOWSKI, H., MOTTA, F.S., SANTANDER-NETO, J., VIANNA, G.M.S., \& LESSA, R. 2017. Rethinking use and trade of pelagic sharks from Brazil. Mar. Policy. 85, 114-122.

BLABER, S.J.M. 2000. Tropical estuarine fishes: ecology, exploitation, and conservation. Fish and Aquatic Resources Series 7. Blackwell Science, CSIRO Marine Research. Cleveland, Queensland, Australia.
BORNATOWSKI, H., ABILHOA, V. \& CHARVET-ALMEIDA, P. 2009. Elasmobranchs of the Paraná Coast, southern Brazil, south-western Atlantic. Mar. Biodivers. Rec. 2:e158.

BORNATOWSKI, H. \& ABILHOA, V. 2012. Tubarões e raias capturadospela pesca artesanal no Paraná: guia de identificação. Curitiba, Paraná: Hori Consultoria Ambiental. Available from: http://www.hori.bio.br/cadernos/23-HCT4.pdf.

BORNATOWSKI, H., BRAGA, R.R., ABILHOA, V. \& CORRÊA, M.F.M. 2014a. Feeding ecology and trophic comparisons of six shark species in a coastal ecosystem off southern Brazil. J. Fish Biol. 85(2):246-263.

BORNATOWSKI, H., SANTOS, L., ROBERT, M.D.C. \& WEISER, P.A. 2014 b. Occurrence of the narrowmouth catshark Schroederichthys bivius (Chondrichthyes: Scyliorhinidae) in southern Brazil. Mar. Biodivers. Rec. 7:e51.

BRANCO, J.O. \& VERANI, J.R. 2006. Pesca do camarão sete-barbas e sua fauna acompanhante, na Armação do Itapocoroy, Penha, SC. In: Bases ecológicas para um desenvolvimento sustentável: estudos de caso em Penha, SC. J. O. Branco, A. W. C. Marenzi (Eds). Editora UNIVALI (Universidade do Vale do Itajaí), Itajaí́, SC, pp. 153-170.

BRANDINI, F. 2014. Marine biodiversity and sustainability of fishing resources in Brazil: a case study of the coast of Paraná state. Reg. Environ. Chang. 14(6):2127-2137.

BRIGGS, J.C. \& BOWEN, B.W. 2012. A realignment of marine biogeographic provinces with particular reference to fish distributions. J Biogeogr 39:12-30.

CARNIEL, V.L. 2008. Interação de aves costeiras com descartes oriundos da pesca artesanal no litoral centro-sul Paranáense. Dissertação de Mestrado, Federal University of Paraná (UFPR), Paraná.

CARVALHO-FILHO, A., SANTOS, S. \& SAMPAIO, I. 2010. Macrodon atricauda (Günther, 1880) (Perciformes: Sciaenidae), a valid species from the southwestern Atlantic, with comments on its conservation. Zootaxa. 2519:48-58.

CASTELLO, J.P. 1994. Oceanografia Biológica (nécton). In Diagnóstico ambiental oceânico e costeiro das regiões sul e sudeste do Brasil. N. Yamaguti, M. Corrêa, \& B. Ledo, Eds. Rio Grande do Sul. 361-379.

CATTANI, A.P., SANTOS, L.O., SPACH, H.L., BUDEL, B.R. \& GUANAIS, J.H.D.G. 2011. Avaliação da ictiofauna da fauna acompanhante da pesca do camarão sete-barbas do município de Pontal do Paraná, litoral do Paraná, Brasil. Bol. do Inst. da Pesca. 37(2):247-260.

CEPENE. 2005. Lista de peixes marinhos e estuarinos permitidos à captura. 3(1) (http://ibama.gov.br/biodiversidade-aquatica/aquariofilia/lista-de-peixespermitidos-para-pesca?id=969)

CHAVES, P.T.C. \& CORRÊA, M.F.M. 1998. Composição ictiofaunística da área de manguezal da Baía de Guaratuba, Paraná, Brasil. Rev. Bras. Zool. 15(1):195-202.

CHAVES, P.T.C. \& ROBERT, M.C. 2003. Embarcações, artes e procedimentos da pesca artesanal no litoral Sul do Estado do Paraná, Brasil (Boats, gears and procedures of the artisanal fishing at the southern coast of Paraná state, Brazil). Atlântica, 25: 53-59.

CHAVES, P.T.C. \& VENDEL, A.L. 2001. Nota complementar sobre a composição ictiofaunística da Baía de Guaratuba, Paraná, Brasil. Rev. Bras. Zool. 18(suppl 1):349-352.

CHAVES, P.T.C., COVA-GRANDO, G. \& CALLUF, C. 2003. Demersal ichthyofauna in a continental shelf region on the south coast of Brazil exposed to shrimp trawl fisheries. Acta Biol. Paraná. 32(4):69-82.

CHEUNG, W.W.L., PITCHER, T.J. \& PAULY, D. 2005. A fuzzy logic expert system to estimate intrinsic extinction vulnerabilities of marine fishes to fishing. Biol. Conserv. 124(1):97-111.

CONTENTE, R.F., STEFANONI, M.F. \& SPACH, H.L. 2011. Fish assemblage structure in an estuary of the Atlantic Forest biodiversity hotspot (southern Brazil). Ichthyol. Res. 58(1):38-50.

CORRÊA, M.F.M., CORDEIRO, A.A.M. \& JUSTI, I.M. 1986. Catálogo dos peixes marinhos da coleção da divisão de zoologia e geologia da prefeitura municipal de Curitiba - I. Rev. Nerítica. 1(1): 1-83.

COSTA, L. \& CHAVES, P.T.C. 2006. Elasmobrânquios capturados pela pesca artesanal na costa sul do Paraná e norte de Santa Catarina, Brasil. Biota Neotrop. 6(3) : http://www.biotaneotropica.org.br/v6n3/pt/ abstract?article+bn02706032006 
CRAIG, M.T. \& HASTINGS, P.A. 2007. A molecular phylogeny of the groupers of the subfamily Epinephelinae (Serranidae) with a revised classification of the Epinephelini. Ichthyol. Res. 54(1):1-17.

DARIO, F., ALVES, C.B.M., BOOS, H. et al. 2015. A better way forward for Brazil's fisheries. Science. 347:1079.

DAROS, F.A., BUENO, L.S., VILAR, C.C., PASSOS, A.C. \& SPACH, H.L. 2012 Checklist of rocky reef fishes from the Currais Archipelago and Itacolomis Island, Paraná state, Brazil. Check List. 8(3):349-354.

ESCHMEYER, W.N., FRICKE, R. \& VAN DER LAAN, R. 2014. Catalog of fishes: genera, species, references. V. 3882. (W.N. Eschmeyer, R. Fricke, \& R. van der Laan, Eds.) http://www.calacademy.org/research/ichthyology/catalog/

FÉLIX, F.C., SPACH, H.L., MORO, P.S., HACKRADT, C.W., QUEIROZ, G.M.L.N. \& HOSTIM-SILVA, M. 2007a. Ichthyofauna composition across a wave: energy gradient on Southern Brazil beaches. Brazilian J. Oceanogr. 55(4):281-292.

FÉLIX, F.C., SPACH, H.L., MORO, P.S., SCHWARZ, R.J., SANTOS, C., HACKRADT, C.W., HOSTIM-SILVA, M. \& FÉLIX, F.C. 2007b. Utilization patterns of surf zone inhabiting fish from beaches in Southern Brazil. Panam. J. Aquat. Sci. 2(1):27-39.

FÉLIX-HACKRADT, F.C., SPACH, H.L., MORO, P.S., PICHLER, H.A., MAGGI, A.S., HOSTIM-SILVA, M., HACKRADT, C.W. \& HACKRADT, F.C.F. 2010 Diel and tidal effects on surf zone fish fauna in Southern Brazil. Lat. Am. J. Aquat. Res. 38(3):447-460.

FIGUEIREDO, J.L. \& MENEZES, N.A. 2009. Manual de peixes marinhos do sudeste do Brasil. Volumes I, II, III, V. Museu de Zoologia da Universidade de São Paulo, São Paulo.

FLOETER, S.R., ROCHA, L.A., ROBERTSON, D.R., JOYEUX, J.C., SMITHVANIZ, W.F., WIRTZ, P., EDWARDS, A.J., BARREIROS, J.P., et al. 2008 Atlantic reef fish biogeography and evolution. J. Biogeogr. 35:22-47.

FROESE, R. \& PAULY, D. 2017. World Wide Web electronic publication. Available: http://www.fishbase.org/search.php [2017, May 15].

GODEFROID, R.S., SPACH, H.L., SANTOS, C., MACLAREN, G. \& SCHWARZ jr., R. 2004. Mudanças temporais na abundância e diversidade da fauna de peixes do infralitoral raso de uma praia, sul do Brasil. Iheringia. Série Zool. 94(1):95-104

GOMES I.D. \& CHAVES P.T. 2006. Ictiofauna integrante da pesca de arrasto camaroeiro no litoral sul do estado do Paraná, Brasil. Fish faunal composition in the shrimp fisheries at the southern coast of Paraná, Brazil. Bioikos 20(1): 9-13.

GUANAIS, J.H.D.G., MEDEIROS, R.P., MCCONNEY, P.A. 2015. Designing a framework for addressing bycatch problems in Brazilian small-scale trawl fisheries. Marine Policy 51, 111-118.

HACKRADT, C.W., PICHLER, H.A., FÉLIX, F.C., SCHWARZ jr., R., SILVA, L.O. \& SPACH, H.L. 2009. A estrutura da comunidade de peixes em praias de baixa energia do complexo estuarino da Baía de Paranaguá, Brasil. Rev. Bras. Zoociências. 11(3):231-242.

IPARDES (Parana Institute of Economic and Social Development), 1981. Comercialização do pescado no litoral paranaense. Secretaria do Estado de Planejamento, Curitiba, pp. 179.

IGNÁCIO, J.M. \& SPACH, H.L. 2010. Variação entre o dia e a noite nas características da ictiofauna do infralitoral raso do Maciel, Baía de Paranaguá, Paraná. 32(2):163-176.

IUCN. 2017. The IUCN red list of threatened species. International ed. IUCN Global Species Programme Red List Unit. Available: http://www.iucnredlist.org/.

LAMAS, R.A., LÚCIA, C., BIANCO, D. \& CONTENTE, R.F. 2016. Checklist of the fish fauna of the Araçá Bay, São Sebastião. Check List 12(6): 2004.

LUIZ JR, O.J., CARVALHO-FILHO, A., FERREIRA, C.E.L., FLOETER, S.R., LUIZ GASPARINI, J. \& SAZIMA, I. 2008. The reef fish assemblage of the Laje de Santos Marine State Park, Southwestern Atlantic: annotated checklist with comments on abundance, distribution, trophic structure, symbiotic associations, and conservation. Zootaxa. 1807:1-25.

MARCENIUK, A.P. 2005. Chave para identificacao das espécies de bagres marinos (Siluriformes, Ariidae) da costa brasilera. Bol. do Inst. da Pesca. 31(2):89-101.
MENEZES, N.A., BUCKUP, P.A., FIGUEIREDO, J.L. \& MOURA, R.L. 2003. Catálogo das Espécies de Peixes Marinhos do Brasil. Museu de Zoologia da USP. São Paulo.

MENEZES, N.A., OLIVEIRA, C. \& NIRCHIO, M. 2010. An old taxonomic dilemma: the identity of the western south Atlantic lebranche mullet (Teleostei Perciformes: Mugilidae). Zootaxa. 2519:59-68.

MENNI, R.C., JAUREGUIZAR, A.J., STEHMANN, M.F.W. \& LUCIFORA, L.O. 2010. Marine biodiversity at the community level: zoogeography of sharks, skates, rays and chimaeras in the southwestern Atlantic. Biodivers. Conserv. 19(3): 775-796.

MMA 2014. Portaria No445 de 7 de setembro de 2014. [ (accessed in 9 May 2017)

MORAES, L.E., ROMERO, R., ROCHA, G.R.A. \& MOURA, R.L. 2009. Ictiofauna demersal da plataforma continental interna ao largo de Ilhéus, Bahia, Brasil. Biota Neotrop. 9(4): http://www.biotaneotropica.org.br/v9n4/en/abstract?in ventory+bn01409042009

MUSICK, J.A., HARBIN, M.M. \& COMPAGNO, J.V. 2004. Historical Zoogeography of the Selachii. In Biology of Sharks and Their Relatives. V. 20043354. (J. Musick, J. Carrier, \& M. Heithaus, Eds.) (Marine Biology). CRC Press.

MUTO, E.Y., SOARES, L.S.H. \& ROSSI-WONGTSCHOWSKI, C.L.D.B 2000. Demersal fish assemblages off São Sebastião, southeastern Brazil structure and environmental conditioning factors (summer 1994). Rev. Bras. Oceanogr. 48(1):09-27.

NELSON, J.S., GRANDE, T.C., WILSON, M.V.H. 2016. Fishes of the world Fifth Edition, John Wiley \& Sons, New York, 752p.

NAHUM, V.J.I., CASTELLO, J.P. \& ROSENTHAL, H. 2009. Special issue: modern fisheries research approaches in Brazil. J. Appl. Ichthyol. 25(3):243-243.

PASSOS, A.C., CONTENTE, R.F., ARAUJO, C.C.V., DAROS, F.A.L.M., SPACH, H.L., ABILHÔA, V. \& FÁVARO, L.F. 2012. Fishes of Paranaguá Estuarine Complex, South West Atlantic. Biota Neotrop. 12(3): http://www. biotaneotropica.org.br/v12n3/en/abstract?inventory+bn01312032012

PICHLER, H.A., SPACH, H.L., GRAY, C.A., BROADHURST, M.K., SCHWARZ, R. \& OLIVEIRA NETO, J.F. 2015. Environmental influences on resident and transient fishes across shallow estuarine beaches and tidal flats in a Brazilian World Heritage area. Estuar. Coast. Shelf Sci. 164:482-492.

PICHLER, H.A., GRAY, C.A., BROADHURST, M.K., SPACH, H.L. \& NAGELKERKEN, I. 2017. Seasonal and environmental influences on recruitment patterns and habitat usage among resident and transient fishes in a World Heritage Site subtropical estuary. J. Fish Biol. 90(1):396-416.

POSSATTO, F.E., BROADHURST, M.K., GRAY, C.A., SPACH, H.L. \& LAMOUR, M.R. 2017. Spatiotemporal variation among demersal ichthyofauna in a subtropical estuary bordering World Heritage-listed and marine protected areas: implications for resource management. Mar. Freshw. Res. 68(4):703-717.

ROBERT, M.C.; CHAVES, P.T.C. 2006. Dinâmica da atividade pesqueira artesanal em duas comunidades da regia o litora`nea limı’trofe Santa Catarina-Paraná, Brasil (Dynamics of the artisanal fishing activity in two communities on the south coast of Brazil). Bol. Inst. Pesca 32: 15-23.

ROBERT, R.; BORZONE, C.A.; NATIVIDADE, C.D. 2007. Os camarões da fauna acompanhante na pesca dirigida ao camarão-sete-barbas (Xiphopenaeus kroyeri) no litoral do Paraná (Shrimp composition of the sea bob (Xiphopenaeus kroyeri) fishery by-catch at the coast of Paraná). Bol. Inst. Pesca. 33: 237-246

ROCHA, G.R.A. \& ROSSI-WONGTSCHOWSKI, C.L.D.B. 1998. Demersal fish community on the inner shelf of Ubatuba, southeastern Brazil. Rev. Bras. Oceanogr. 46(2):93-109.

ROSA, R.S. \& GADIG, O.B.F. 2014. Conhecimento da diversidade dos Chondrichthyes marinhos no Brasil: a contribuição de José Lima de Figueiredo. Arquivos de Zoologia. São Paulo. Vol. 45(esp.):89-104

ROSSI-WONGTSCHOWSKI, C.L.D.B., VAZ-DOS-SANTOS, A.M. \& SILIPRANDI, C.C. 2014. Checklist of the marine fishes collected during hydroacoustic surveys in the southeastern brazilian bight from 1995 to 2010 Arq. Zool. 45(esp):73-88

SANTOS, C. 2006. Comunidade de peixes demersais e ciclo reprodutivo de quatro espécies da família Sciaenidae na plataforma interna entre Superagüi e Praia de Leste, PR. Curitiba. PhD Thesis, Federal University of Paraná, Paraná. 
SANTOS, C., CORTEllet, G.M., ARAUJO, K.C. \& SPACH, H.L. 2006. Estrutura populacional da raia-viola Zapteryx brevirostris (Chondrichthyes, Rhinobatidae) na plataforma adjacente à Baía de Paranaguá, PR. Acta Biol. Leopondensia. 28(1):32-37.

SANTOS, L. O., CATTANI, A.P. \& SPACH, H.L. 2016. Ictiofauna acompanhante da pesca de arrasto para embarcações acima de 45 hp no litoral do Paraná, Brasil. Bol. do Inst. Pesca. 42(4):816-830.

SCHWARZ-JUNIOR, R. 2009. Composição, estrutura e abundância da ictiofauna capturada com redes de arrasto de portas na plataforma continental interna rasa do litoral do Paraná. PhD Thesis, Federal University of Paraná, Paraná.

SMITH, W.L. \& CRAIG, M.T. 2007. Casting the Percomorph Net Widely: The Importance of Broad Taxonomic Sampling in the Search for the Placement of Serranid and Percid Fishes. Copeia. (1):35-55.
SPIER, D. 2016. Integrating ecological niche modelling and beta diversity analysis in marine systems management. $\mathrm{PhD}$ Thesis, Federal University of Paraná, Paraná.

VOOREN C.M., KLIPPEL S. and GALINAA.B. 2005. Elasmobrânquios das águas costeiras da Plataforma Sul. In Vooren C.M. and Klippel S. (eds) Ações para conservação de tubarões e raias no sul do Brasil, Capítulo 7. Porto Alegre: Igará, pp. 114-120.

Received: $19 / 05 / 2017$

Revised: 12/01/2018

Accepted: 24/01/2018

Published online: 01/03/2018 